\title{
PAISAJE EN MOVIMIENTO, UNA INTEGRACIÓN DEL TERRITORIO DE CASPANA DESDE LO RITUAL Y LO ANCESTRAL
}

\author{
LANDSCAPE OF MOVEMENT, AN INTEGRATION OF CASPANA TERRITORY \\ FROM THE RITUAL AND THE ANCESTRAL
}

\author{
Melisa Miranda Correa*
}

\begin{abstract}
Este artículo revisa el concepto de "paisajes en movimiento" como una expresión del uso y percepción de territorios de pueblos originarios. Esta perspectiva integra la protección de registros arqueológicos con el patrimonio inmaterial que es albergado por las comunidades. Para articular un paisaje en movimiento se revisan diferentes antecedentes históricos realizados por antropólogos y arqueólogos que dan cuenta de patrones de movimiento, tanto en la escala del camino del Inca como hacia sitios ceremoniales de Alto Loa. Este material se complementa con una actividad de mapeo cultural realizado junto con la comunidad de Caspana, región de Antofagasta, cuyo objetivo era identificar lugares significativos para la comunidad asociados a patrones de movimiento. Los resultados del mapeo se presentan como una articulación territorial doble: el espacio ritual, de uso intensivo en donde la comunidad de Caspana realiza las fiestas religiosas, peregrinaciones, procesiones rituales y sacralización de lugares; y el espacio ancestral, donde familias solían visitar estancias y capillas ubicadas entre los pueblos durante los festejos religiosos, entre otras actividades. Esta mirada permite integrar revisiones del pasado con perspectivas actuales de quienes los habitan, siendo un potencial para nuevas metodologías de participación para la gestión patrimonial.
\end{abstract}

Palabras claves: Paisaje en movimiento, camino del Inca, patrimonio inmaterial, mapeo cultural.

This article reviews the concept of "landscapes in movement" as an expression of the use and perception of territories of native peoples. This perspective integrates the protection of archaeological sites and the intangible heritage of communities. Too articulate a landscape in movement, different historical antecedents made by anthropologists and archaeologists that account for movement patterns are reviewed, both on the scale of the Inca road and towards ceremonial sites in Alto Loa. This material is complemented by a cultural mapping activity conducted with the community of Caspana, Antofagasta region, whose objective was to identify significant places for the community associated with movement patterns. The results of the mapping are presented as a double territorial articulation: the ritual territory, of intensive use where the community of Caspana carries out religious festivals, pilgrimages, ritual processions, and sacralization of places; and the ancestral territory, where families used to visit estancias and chapels located between towns during religious festivals, among other activities. This view allows integrating reviews of the past with current perspectives of those who inhabit them, being a potential for new participation methodologies for heritage management.

Key words: Landscape of movement, Inca road, intangible heritage, cultural map.

\section{Introducción}

El patrimonio intangible reconoce el patrimonio cultural como una transición colectiva de conocimiento, como la tradición oral, los rituales, los usos sociales, las celebraciones, el uso de recursos y las técnicas artesanales (Brugman, 2012). Mediante la Convención del Patrimonio Mundial, UNESCO apoya el desarrollo de políticas de patrimonio cultural en tres áreas: creación de sectores culturales dinámicos, protección y conservación del patrimonio y patrimonio cultural como transmisión de identidades colectivas (Brugman, 2012). En este contexto, existe un número creciente de sitios protegidos inscritos en la lista del Patrimonio Mundial de la UNESCO. En los países latinoamericanos, una de las principales características de estos sitios es que están relacionados con civilizaciones y pueblos originarios. Un ejemplo es el camino del Inca que solía conectar dicho imperio con las comunidades conquistadas. Hoy se pueden evidenciar sus huellas e infraestructura en cinco países de América Latina: Ecuador, Perú, Bolivia, Chile y Argentina. Estos países solicitaron conjuntamente el estatus de Patrimonio Mundial de la UNESCO, bajo la categoría de "itinerario cultural" (UNESCO 2014a). Esta categoría implicó un enfoque en las comunidades alrededor de estos caminos, bajo el

* Universidad de Edimburgo. Edimburgo, Reino Unido. Dirección postal: Av. Irarrázaval 4900, departamento 503-b, Santiago, Chile. Correo electrónico: m.miranda@ed.ac.uk 
supuesto de que la mayoría pertenece a comunidades indígenas. La complejidad presentada en la identificación de los caminos (respecto de su origen y si fueron construidas por los incas o las culturas presentadas) cambió el enfoque de prácticas de conservación y programas de desarrollo para la gestión del patrimonio por parte de las comunidades locales (Monumentos 2016). A pesar del enfoque en el patrimonio cultural inmaterial de estas comunidades, estudios en la zona se han centrado mayoritariamente en configurar la documentación arqueológica para proteger el patrimonio material de diferentes indicios de poblados antiguos, desde pucaras hasta los sitios exactos por donde pasa el camino (UNESCO 2014b).

Hoy los sitios arqueológicos están amparados bajo la Ley $\mathrm{N}^{\circ} 17.288$ del Consejo Nacional de Monumentos (CMN). Un monumento implica que el edificio y el sitio arqueológico deben permanecer sin cambios y las comunidades deben solicitar autorización para cualquier modificación que decidieran hacer sobre él (MINEDUC, 1970, 1990). Además, el patrimonio inmaterial se protege por medio de la implementación de la convención para la Salvaguardia del patrimonio cultural inmaterial (UNESCO 2003) adscrito por Chile el 2008. Es decir, la gestión entre lo cultural/inmaterial y lo arqueológico/ histórico no ocurre de manera integrada. Un ejemplo es la iglesia de Caspana, monumento nacional donde se celebra la fiesta tradicional en celebración a la virgen de la Candelaria:

\begin{abstract}
"Nosotros ya arrastramos un problema con la Iglesia, porque en el año 51 fue nombrada monumento histórico y eso significa para nosotros pedir permiso. Para cambiarle el techo fue una batalla" (Entrevistada A 2018).
\end{abstract}

Este es un ejemplo que grafica la distancia entre el patrimonio material e inmaterial. El estudio de paisajes en movimientos se enfoca en las diferentes rutas y caminos desde una mirada arqueológica, sin embargo el objetivo final es entender el estudio de paisajes como una herramienta para comprender el pasado, la historia de estas comunidades y su estructura social (Snead, Erickson, and Daring, 2009). El objetivo de este artículo es presentar un enfoque alternativo de la relación entre el patrimonio arqueológico y el patrimonio cultural de comunidades involucradas en el camino del Inca. Caspana, a pesar de no estar hoy incluida en la lista del patrimonio mundial sí posee sitios Incas y huellas del camino (Adán y Uribe 2005; José Berenguer y Salazar 2017). Las razones y conflictos que llevaron a la salida de Caspana del proyecto Qhapaq Nan no son explorados en este artículo. La noción de "movimiento" y la conexión de la comunidad con el pasado se exploran mediante una metodología de paisaje en movimiento que busca ubicar la celebración de fiestas religiosas, peregrinaciones y procesiones de rituales hasta la cima de las colinas, como prácticas reales que describen un paisaje tradicional de movimiento. El potencial de este tipo de registro es que podrían convertirse en una guía para desarrollar nuevas metodologías de participación para la gestión patrimonial, que incluyan la organización espacial entendida por las comunidades y de manera integrada a la gestión de sitios arqueológicos.

La primera parte del artículo busca situar el concepto de paisaje en movimiento en la presente discusión, argumentando que permite integrar epistemologías relacionadas con prácticas rituales, al describir lugares no visibles como lugares sagrados, rituales, memoria con caminos que conectan estos territorios. Luego, se hace una revisión de los caminos del Inca como un paisaje en movimiento a partir de la revisión del trabajo etnohistórico realizado por arqueólogos durante las últimas décadas acerca de la región andina, el espacio, la organización social, los hitos del paisaje y los patrones de ocupación, entre otros. Finalmente, la lectura se acerca hacia el movimiento regional de Alto Loa y finalmente se analiza el paisaje en movimiento en Caspana, un pequeño pueblo que practica ciertas procesiones rituales que articulan el paisaje a base del desplazamiento de las personas. Esta última lectura se apoya en algunas entrevistas realizadas acerca de un modelo tridimensional montado en la comunidad, practicando mapeo cultural, que finalmente articulan el territorio de Caspana en dos categorías: el espacio ancestral y el espacio ritual.

\section{El rol de los caminos en un paisaje en movimiento}

La idea de paisajes en movimiento fue estructurada en la conferencia Landscapes of movement trails, paths, and roads in Anthropological perspective. Allí se destacó cómo la teoría del paisaje habría influido en la práctica antropológica, creando un 
marco analítico más flexible de las prácticas sociales de las culturas antiguas e incorporando aspectos de patrones y escalas, contexto y asociación (Snead, Erickson, and Daring, 2009, p. 3). Los arqueólogos participantes de esta conferencia se preguntaban cómo el espacio era organizado por las culturas antiguas. La respuesta muchas veces se encuentra en las comunidades que hoy habitan dichos territorios y manifiestan un conocimiento heredado en prácticas espaciales y patrones de ocupación. Es así como por medio de etnografías del pasado es posible analizar un lugar por su contexto, habitantes, patrimonio, políticas, tradiciones, simbolismo, puntos de referencia y carreteras (Snead, 2009, p. xvi). Los autores entienden un paisaje en movimiento como un complejo palimpsesto compuesto por tiempo, memoria, simbolismo, tradiciones y el uso de la tierra de culturas antiguas, la mayoría de ellas culturas indígenas de todo el mundo (Snead, Erickson, and Daring, 2009). Los senderos Hopi en Estados Unidos (Ferguson, Lenis, and Kuwanwiswma, 2009) \{Ferguson, 2009, Kukhepya: Searching for Hopi Trails \}, los senderos Mayas en Guatemala (Keller, 2009), caminos antiguos en Nueva Guinea (Snead, 2009), sistemas de caminos y canales en el Amazonas (Erickson, 2009) y en Australia mediante la interesante narrativa de las Songlines (Clarke, 2003), son solo algunos ejemplos de la compleja gama de paisajes en movimiento en el mundo. Todos los lugares nombrados presentan vestigios de caminos antiguos y, al estudiarlos, es posible comprender la complejidad social y la relación profunda entre comunidades y paisaje.

Desde esta mirada hacia los paisajes, la memoria cumple un rol central y es entendida como un catalizador del movimiento que se desarrolla en el proceso de conectar elementos del paisaje tales como "horizontes, líneas, olores, y colores" (Tilley, 2012, p. 28); conectando las generaciones antiguas con quienes hoy habitan dichos territorios, permitiendo así el trabajo historioetnográfico. Este es el "resultado de la relación entre la memoria y los lugares en una imagen o idea única del mundo externo", o en otras palabras, un mundo cohesivo (Snead, Erickson, and Darling, 2009, p. 52). Es un espacio donde la memoria de un lugar se asocia con un camino, un camino a seguir y es perpetuado por generaciones (Darlin, 2009).

Carreteras, rutas, senderos o caminos son el soporte físico para el movimiento, son posibilidades desde la mirada de Ingold (Ingold, 2012,
2015), o en palabras de Solnit, "una interpretación previa de la mejor manera de atravesar un paisaje" (Solnit, 2002, p. 68). En este discurso, los caminos articulan relaciones complejas entre espacio, lugar y movimiento.

El principal uso de los caminos es la conexión hacia recursos (Erickson, 2009), sin embargo, se complementa con un uso ancestral de los caminos que se asocia con lo sagrado, mediante la realización de rituales, peregrinaciones, la construcción de santuarios, refugios y altares (Ferguson et al., 2009). Además, el viaje en sí mismo es territorializado por elementos construidos en el paisaje, "menhires" como llama Carreri a la "primera modificación física del mapa nómada"(Careri, 2002, p. 56). Otros hitos asociados a los caminos pueden conformarse con un montón de piedras en el lado del camino donde cada viajero crea un recuerdo del viaje, al detenerse y agregarle más piedras (Ingold, 2012) a la manera de "nodos donde el paisaje circundante se dibuja e interpreta" (Tilley, 2012, p. 24).

En Chile solo se ha utilizado el término paisaje en movimiento en una publicación de 2017 por Salazar, Fonck e Irarrázaval, en donde se asocia al sentido de pertenencia y prácticas interculturales de La Araucanía. Un enfoque similar a la publicación de Lazo, Riquelme y Huiliñir-Curío (2020), estudio también ubicado en la zona de La Araucanía. Vale mencionar que los enfoques hacia la movilidad suelen incorporar epistemologías indígenas, las que permiten incorporar ámbitos inmateriales y asociados a la tradición oral que las aproximaciones tradicionales al patrimonio no logran de igual forma. Asimismo, también en la región de La Araucanía se han incorporado alternativas epistemológicas para comprender cómo comunidades Mapuche comprenden el territorio y el paisaje desde lo identitario, desde la idea de "territorios discursivos" (Villanueva, 2019). Es sobre estos discursos e investigaciones que el presente artículo se inserta desde un punto de vista teórico local.

\section{Los Caminos del Inca, un paisaje en movimiento}

La cultura andina, en su complejidad, presenta múltiples paisajes en movimiento que se pueden rastrear desde los tiempos del Inca, quienes heredaron a las culturas contemporáneas ciertas prácticas espaciales y de movimiento que sirven de contexto 
para entender el movimiento, en el caso de estudio en la comunidad de Caspana.

De esta forma, el Tawantinsuyu fue el proyecto político del Imperio Inca, entendido como una integración macrorregional a escala continental (Vitry, 2017). Cada nueva conquista de tierra estaba conectada por un camino, ahora un camino imperial, caminado únicamente por personas autorizadas. Los elementos a lo largo de las carreteras para apoyar este viaje fueron varios: señales, escaleras, puentes, túneles, senderos de piedra y lugares para descansar, muros y senderos elevados, tambos y tambillos (Vitry, 2017).

Los caminos también se conectaban con las cimas de las montañas (ver Figura 1), lugares sagrados para las culturas andinas (Lynch, 1993-1996), debido a que albergan dioses o espíritus (José Berenguer, Aldunate, y Castro, 1982; Besom, 2009). Al igual que en Dreamtime australiano, las montañas representaban huellas dejadas por ancestros y, al mismo tiempo, el origen de los mismos grupos sociales (Besom, 2009; Vitry, 2017, p. 40). La relación entre un mallku (espíritu de la montaña) y un grupo social conforman una huaca, una organización socioespacial que delimita cada territorio andino (Gartner, 1998, p. 266). De esta manera, la huaca es el dispositivo simbólico que organiza el espacio y el territorio en el mundo andino (Sanhueza, 2008, p. 59). Para cristalizar esta relación se construían plataformas en la cima de las colinas, llamadas usnos, como puntos de referencia que representan lugares ceremoniales y desde donde dividían el territorio (Pino Matos, 2016).

El Inca y posteriormente las culturas andinas, también utilizaron mojones (ver Figura 2), como pilas de rocas, para delinear límites sociales y familiares (Pino Matos, 2016), no como una cerca continua sino como puntos de referencia utilizados en rituales de peregrinación (Harris, 1997). De esta forma la memoria territorial es demarcada por medio de elementos sagrados (Sanhueza, 2008, p. 69). El ritual de caminar sobre los mojones se llamó muyuri y consistía en la realización de caminatas conectando mojones, las que finalizaban en mesas ceremoniales (Sanhueza, 2008, p. 71). Los incas practicaron la tradición de los muyuri como una forma de reconocer la estructura social de las regiones conquistadas. Luego las autoridades españolas repetirían este acto para reforzar su autoridad (Sanhueza 2008). Es así como españoles se unían junto con los caciques locales o con el jefe en esta práctica, con el objetivo de convertirse en una nueva autoridad, en un acto de identidad y derechos sobre la tierra "conmemorando los espacios colectivos" (Sanhueza, 2008, p. 74). Otro punto de referencia en el paisaje heredado por la cultura andina es la apacheta, la que es confundida con los mojones al ser también una pila de piedra (Lynch, 19931996). La diferencia es que las apachetas se ubican junto a las carreteras utilizadas por los lugareños para viajar entre las aldeas vecinas o para lograr peregrinaciones a las montañas (ver Figura 3). El ritual hacia la apacheta consistirá en ofrecer un pago con el objeto de ganar fuerzas para continuar el viaje (Besom, 2009). A su vez, las apachetas también ayudaban con la visibilidad de los caminos (Berenguer, Cáceres, Sanhueza, y Hernández 2005).

\section{El movimiento regional de Alto Loa}

Una de las áreas conquistadas por el Imperio Inca fue la región norte de Chile, donde varias comunidades Aymara y Atacameña habitan hasta hoy (ver Figura 4). Se consideran comunidades indígenas debido al uso ancestral de la tierra y los recursos locales (Social-development, 2016). En Alto Loa se ubican seis comunidades: Toconce, Caspana, Turi, Ayquina, Lasana y Chiu Chiu. Los Incas llegaron a esta zona cuando ya existía una estructura social, viviendas colectivas llamadas pukaras, producción agrícola, minería y caminos comerciales. Turi, Caspana y Toconce fueron las localidades más pobladas de la región. Para practicar la administración a distancia, las autoridades Incas utilizaron caminos existentes y construyeron nuevos caminos, los que además de cumplir una función política y sagrada, también tenían el papel de transportar productos de las tierras conquistadas como tributo. En Alto Loa se estableció un modelo productivo para apoyar la extracción de plata mediante la construcción de campos de agricultura en terrazas (Salazar, Berenguer, y Vega, 2013; Sinclaire, 2004). Cerro Verde e Incahuasi Inca fueron centros mineros esenciales en donde se construyeron usnus para celebrar rituales incas (José Berenguer y Salazar, 2017).

A pesar del poder y sometimiento que representó el inca, los lugareños lo consideran un momento de prosperidad que generaron encuentros entre la población local, ya que organizaron fiestas y permitieron que las tradiciones locales ceremoniales se desarrollaran en torno a chullpas o lugares de 


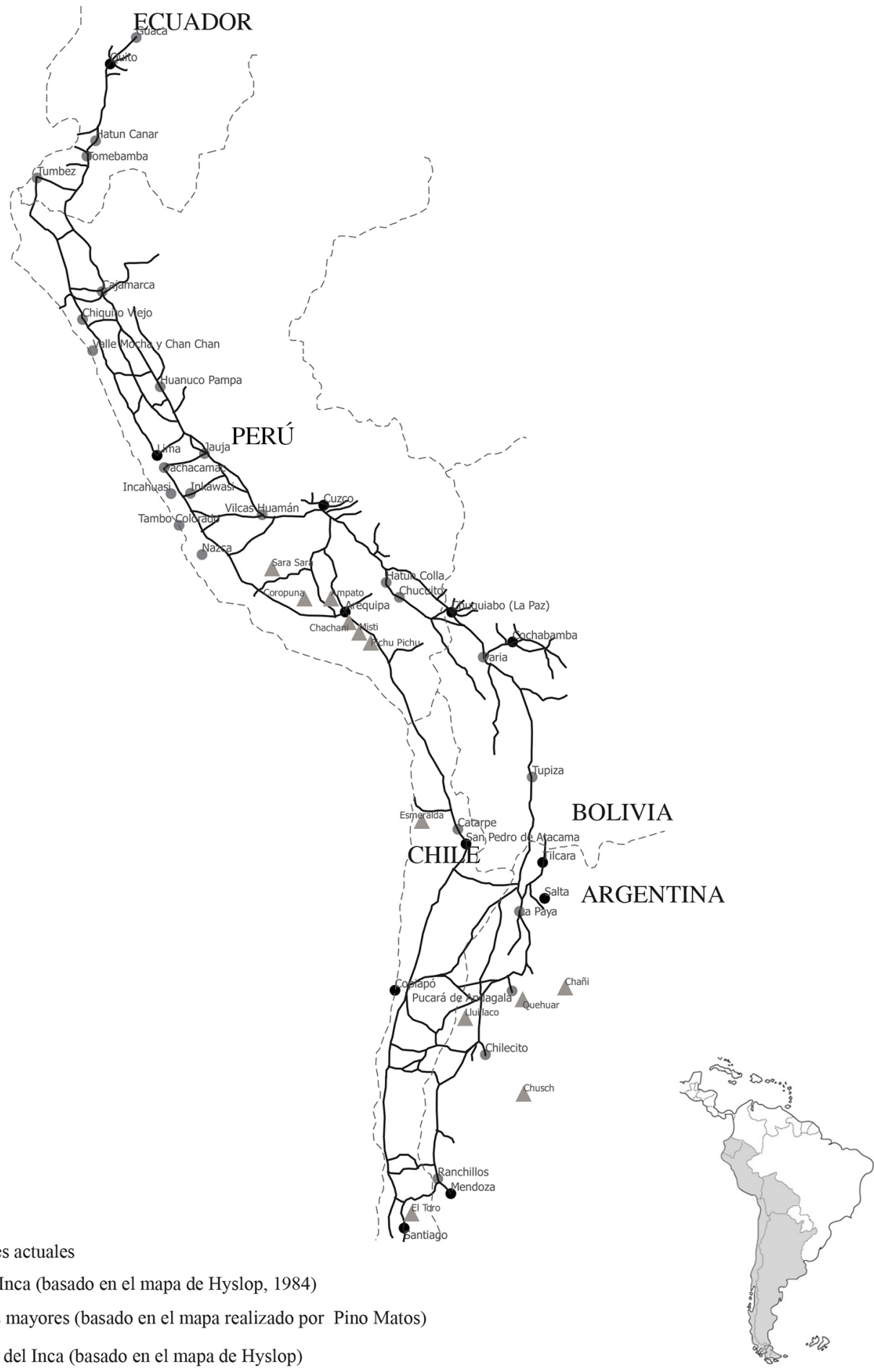

- Ciudades actuales

- Ciudad Inca (basado en el mapa de Hyslop, 1984)

$\triangle$ Mallkus mayores (basado en el mapa realizado por Pino Matos)

Camino del Inca (basado en el mapa de Hyslop)

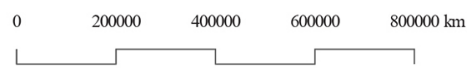

Figura 1. Caminos del Inca junto con los mallkus mayores. Basado en mapa de Hyslop, 1984 y Pino Matos, 2016. 


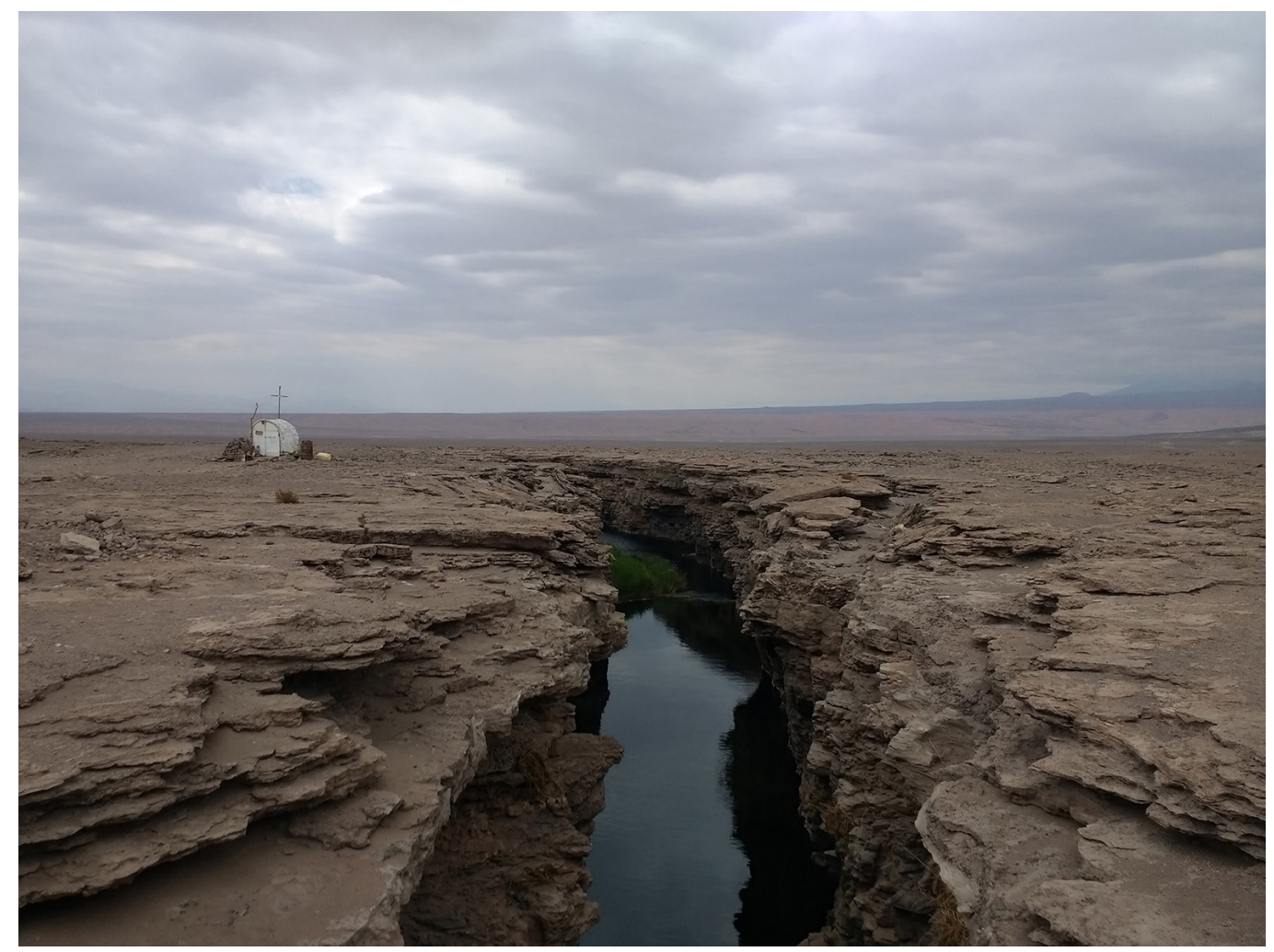

Figura 2. Mojón demarcando el territorio de Caspana junto a la Quebrada del Diablo.

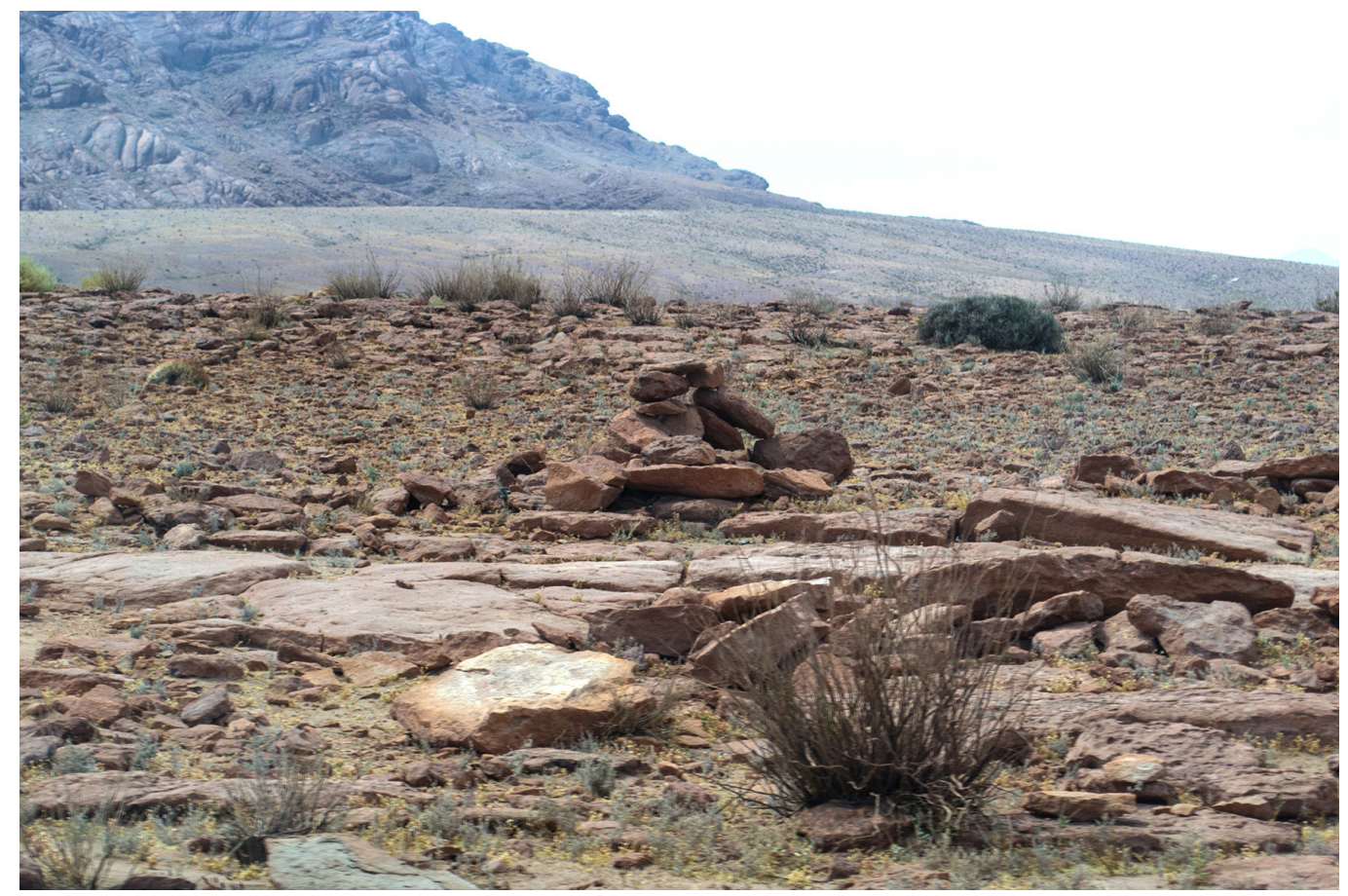

Figura 3. Apacheta junto a camino del inca en cercanías de Caspana. 


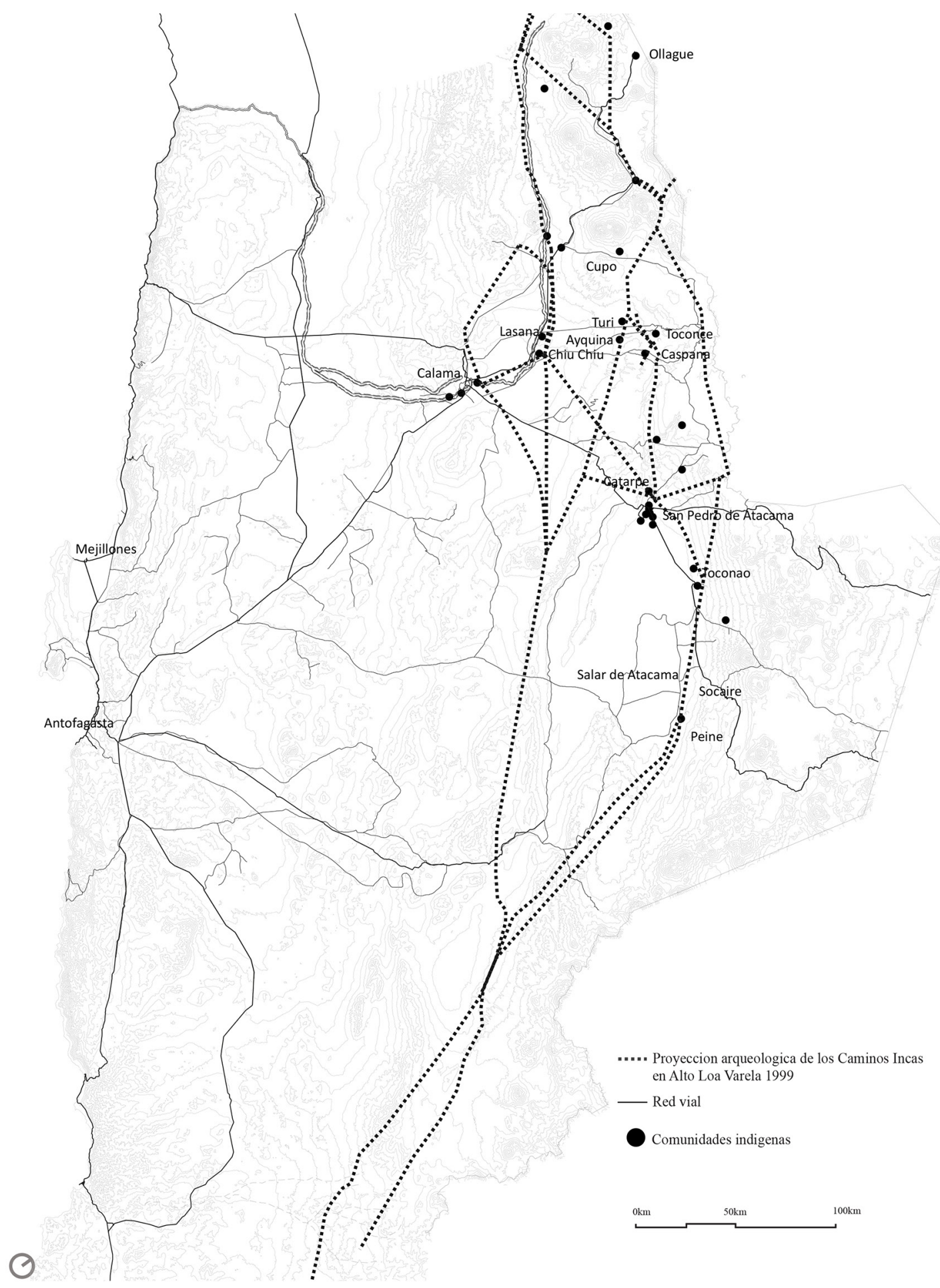

Figura 4. Caminos del Inca y poblados en la región de Antofagasta. Basado en proyección de Varela G. 1999. 
sepulcro (José Berenguer y Salazar, 2017; González, Aguilar, y Garrido, 2015). Finalmente, la memoria del rey inca hoy se fusiona con la memoria de los tiempos antiguos, lugares relacionados con el inca que describen el patrimonio cultural inmaterial que forma parte del paisaje regional (Adán y Uribe, 2005). Dos ejemplos asociados con la forma en que se articula la memoria se pueden evidenciar en la región de Alto Loa, en la laguna Inca Koya, supuestamente de profundidad infinita (ver Figura 5); y en los Baños de Turi, donde el rey, según las historias locales, solía tomar baños milagrosos (ver Figura 6).

La cultura atacameña construía chullpas que albergaban las tumbas de importantes autoridades locales y sobre ella construían altares de piedra con forma rectangular (Castro y Martínez, 1996). La Iglesia Católica en su propósito evangelizador, en su afán por transformar la devoción hacia las montañas o mallkus en un culto católico, construyó capillas sobre las chullpas, y las pilas de rocas fueron transformadas en plataformas con cruces sobre ellas (Lynch, 1993-1996) (ver Figura 7). Además de transformar los elementos construidos sobre el paisaje, se buscó transformar el significado de dichos lugares. Es por ello que por medio de santos buscaron reemplazar la adoración y la devoción a las montañas. Un ejemplo es San Santiago, patrono de Toconce, en donde se descubrió que uno de los altares utilizados en su procesión se orienta hacia el cerro León, asociando al santo con un cerro tutelar (Jose Berenguer et al., 1982). Es así como el símbolo del mallku ha evolucionado desde un elemento propio de lo andino hacia un elemento católico sin perder la organización espacial que representa (Jose Berenguer et al., 1982) (ver Figura 8). Hasta el día de hoy los altares albergan el destino de las peregrinaciones regionales, así como la estructura socio territorial de las antiguas huacas.

La mayor peregrinación en Alto Loa, en cuanto a número de asistentes, se celebra en Ayquina en donde decenas de bailes provenientes de Calama y otros lugares de la región viajan a Ayquina a bailar a la virgen junto con sus respectivas orquestas. Esta tradición revela un significado ritual arraigado en la historia colonial de estas tierras, cuando la devoción popular de los santos católicos fue introducida por los conquistadores españoles y la Iglesia Católica permitió que los taki, culto indígena a las montañas y otros elementos de la región, cantaran y bailaran (Díaz A., Galdames, y Mucous, 2012). Más de 50.000 personas viajan cada septiembre al poblado de Ayquina, el que está habitado regularmente por cincuenta personas (Mercado, 2014). A lo largo de las celebraciones, los bailes y la música guían una procesión hacia hitos relevantes en la ciudad, como la entrada, alrededor de la iglesia y al lado del río (ver Figura 9), como umbrales que abarcan el movimiento de personas y una narración hacia lo sagrado (Eliade, 1959).

Las peregrinaciones en este contexto son una forma de caminar como un acto performativo donde se atraviesa el paisaje (Tilley, 2012); o en palabras de Solnit, caminando en busca de algo intangible (2002, p. 30). Un número significativo de personas que solían vivir en los poblados de Alto Loa ahora viven en grandes ciudades después de emigrar en busca de trabajo para la educación de sus hijos. Las peregrinaciones, los ensayos de los grupos de baile son la forma en que las familias mantienen el contacto con sus raíces, permitiendo que la memoria se active mediante estos rituales.

\section{El paisaje en movimiento de Caspana}

Como parte del caso de estudio en Caspana fue posible articular una metodología aplicada de paisaje en movimiento que se inició con la revisión de publicaciones arqueológicas en la región; seguido por un proceso de mapeo cultural, el que recopiló la historia oral asociada a generaciones anteriores y el uso de paisaje; y finalmente el análisis de los datos recopilados, el que permitió interpretar una articulación espacial entre lo ritual y lo ancestral. Esta metodología se entiende desde la Teoría Fundamentada, es decir, una vez iniciado el proceso de análisis, las categorías presentadas se comparan y revisan con los elementos teóricos revisado en un inicio, convirtiéndose en un proceso cíclico como lo ilustra la Figura 10.

Lo primero que se llevó a cabo fue la elaboración de un mapa de tenencia, ya que así fue requerido por la propia comunidad ${ }^{1}$. Para completar este mapa se realizó un conjunto de entrevistas con el objetivo de identificar y ubicar elementos valiosos del lugar, patrimonio, movimientos, dinámicas, caminos, entre otros muchos puntos de referencia en el paisaje. Posterior a esto se definieron categorías a base de las entrevistas realizadas y una vez articulado el análisis este fue llevado de vuelta a la comunidad, en donde se revisaron los resultados y se acordó enfocar un trabajo posterior en lo que se definió como el "espacio ritual". A continuación 


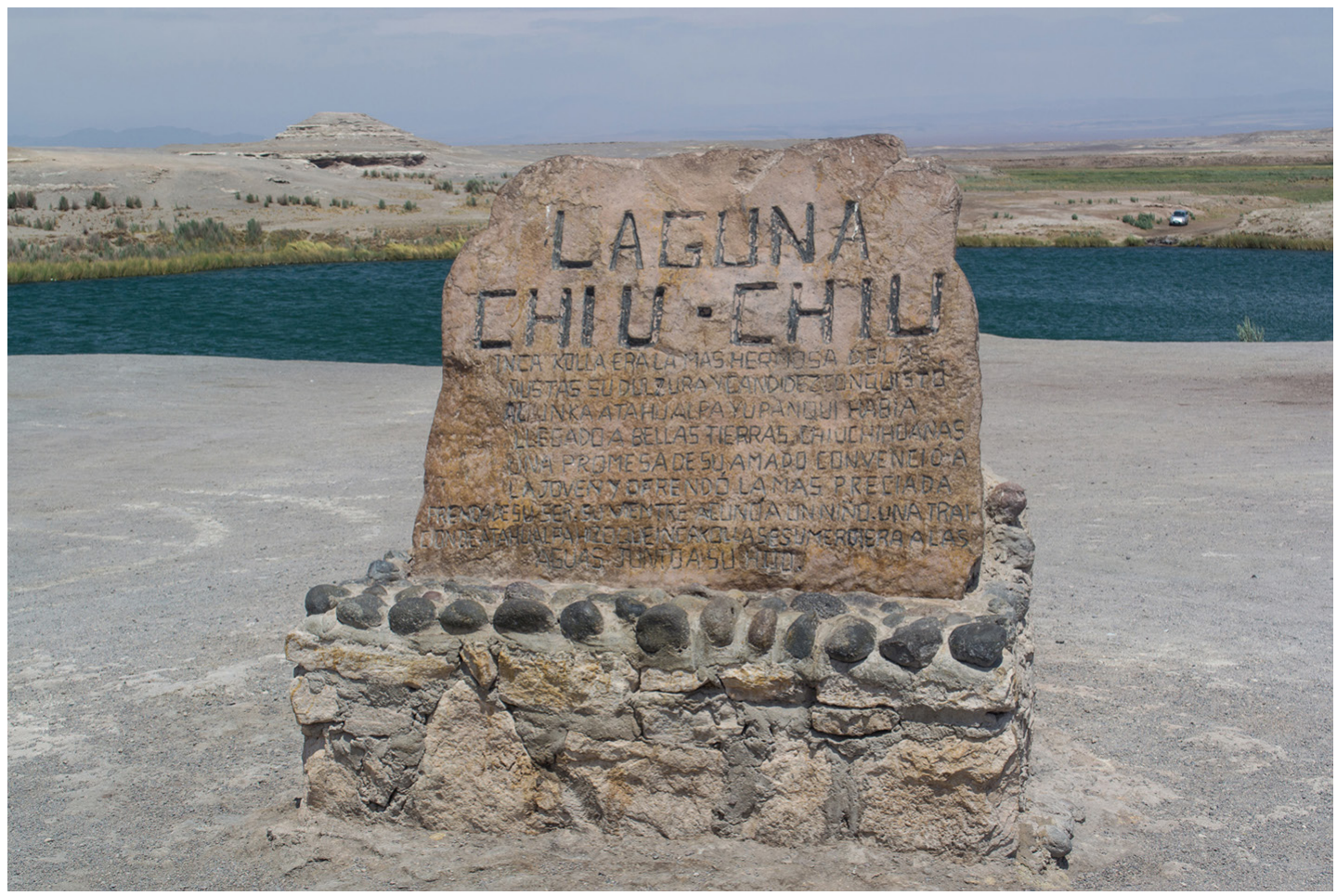

Figura 5. Laguna Inka Kolla, Chiu Chiu.

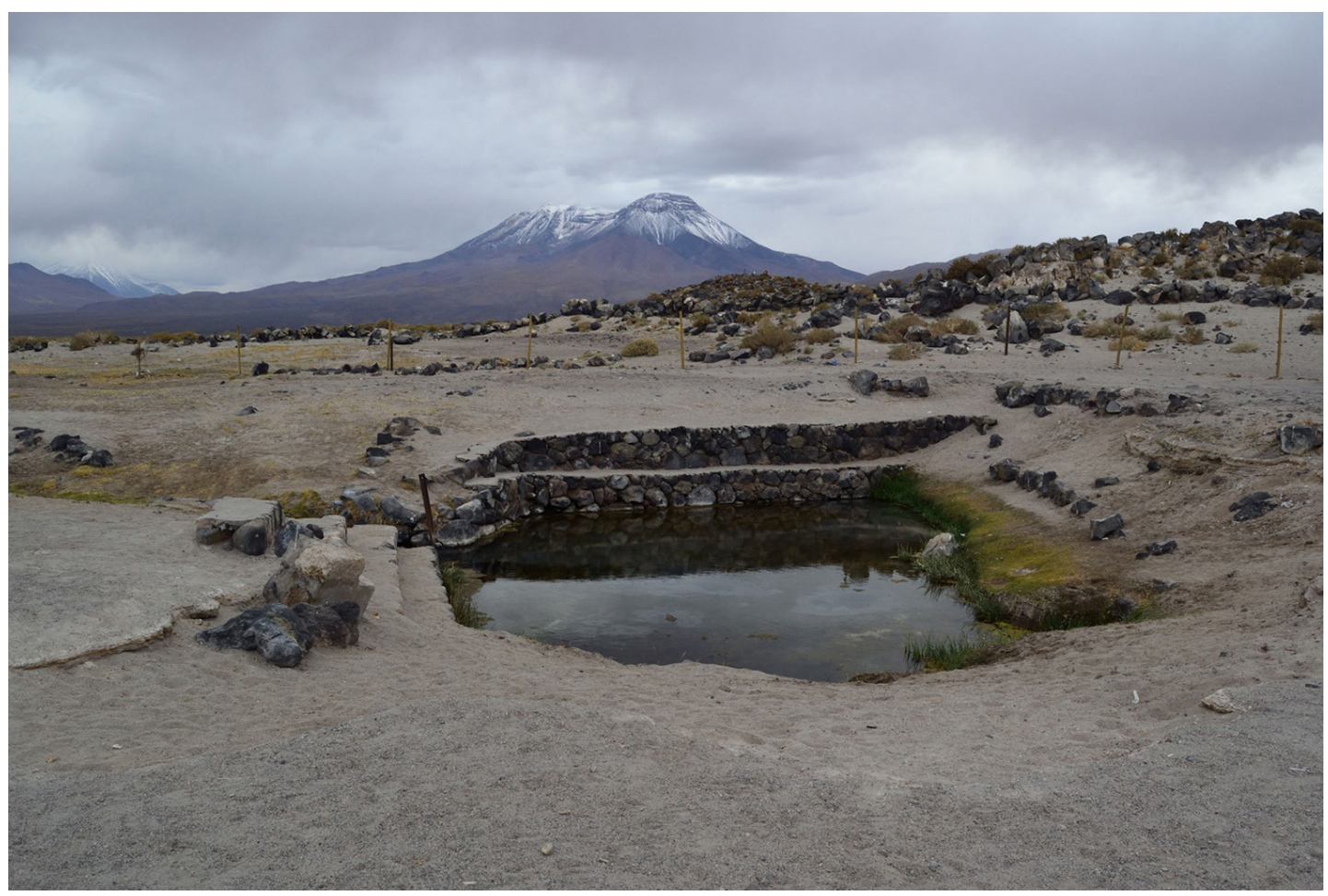

Figura 6. Baños de Turi. 


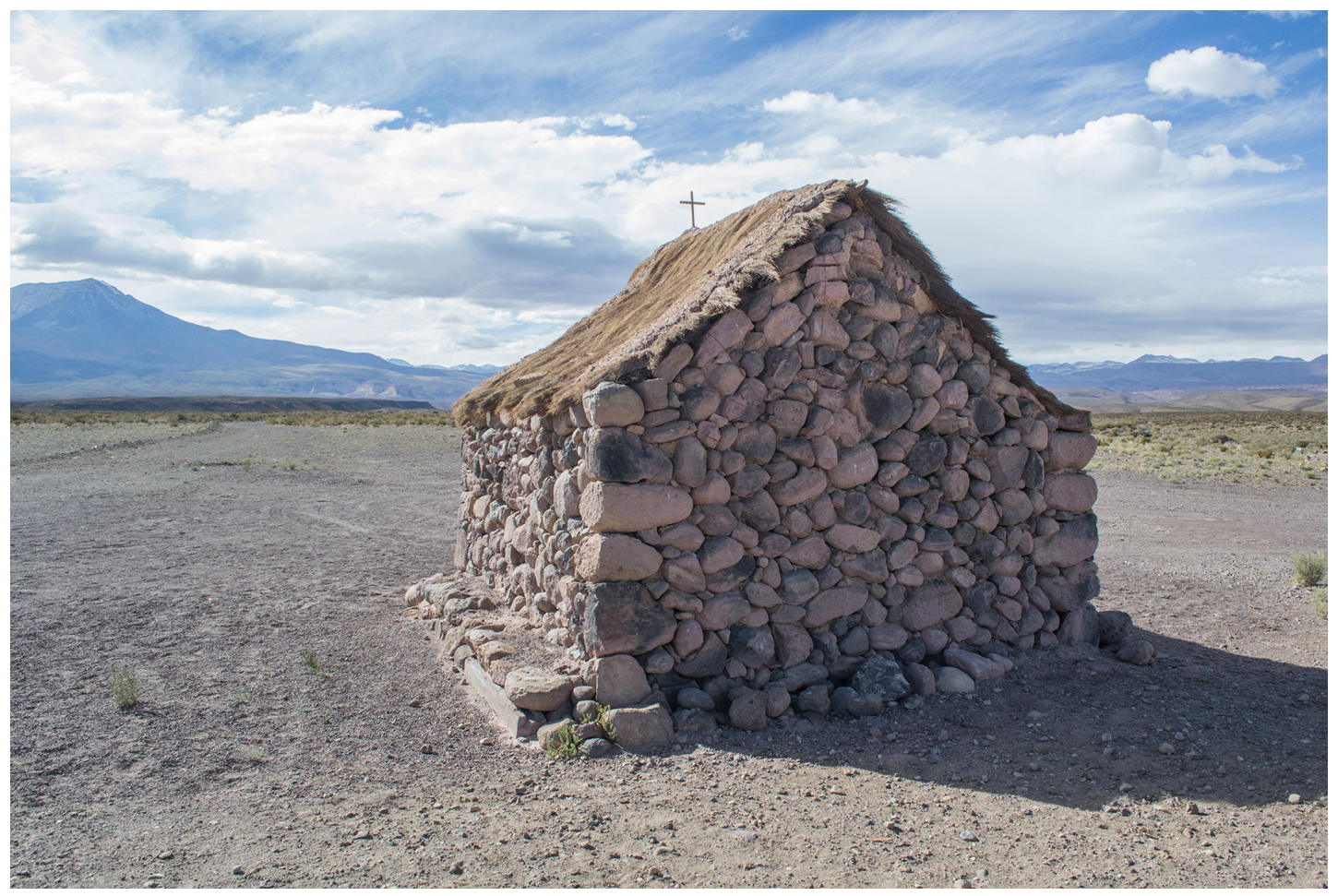

Figura 7. Altar para la peregrinación de la virgen de Ayquina.

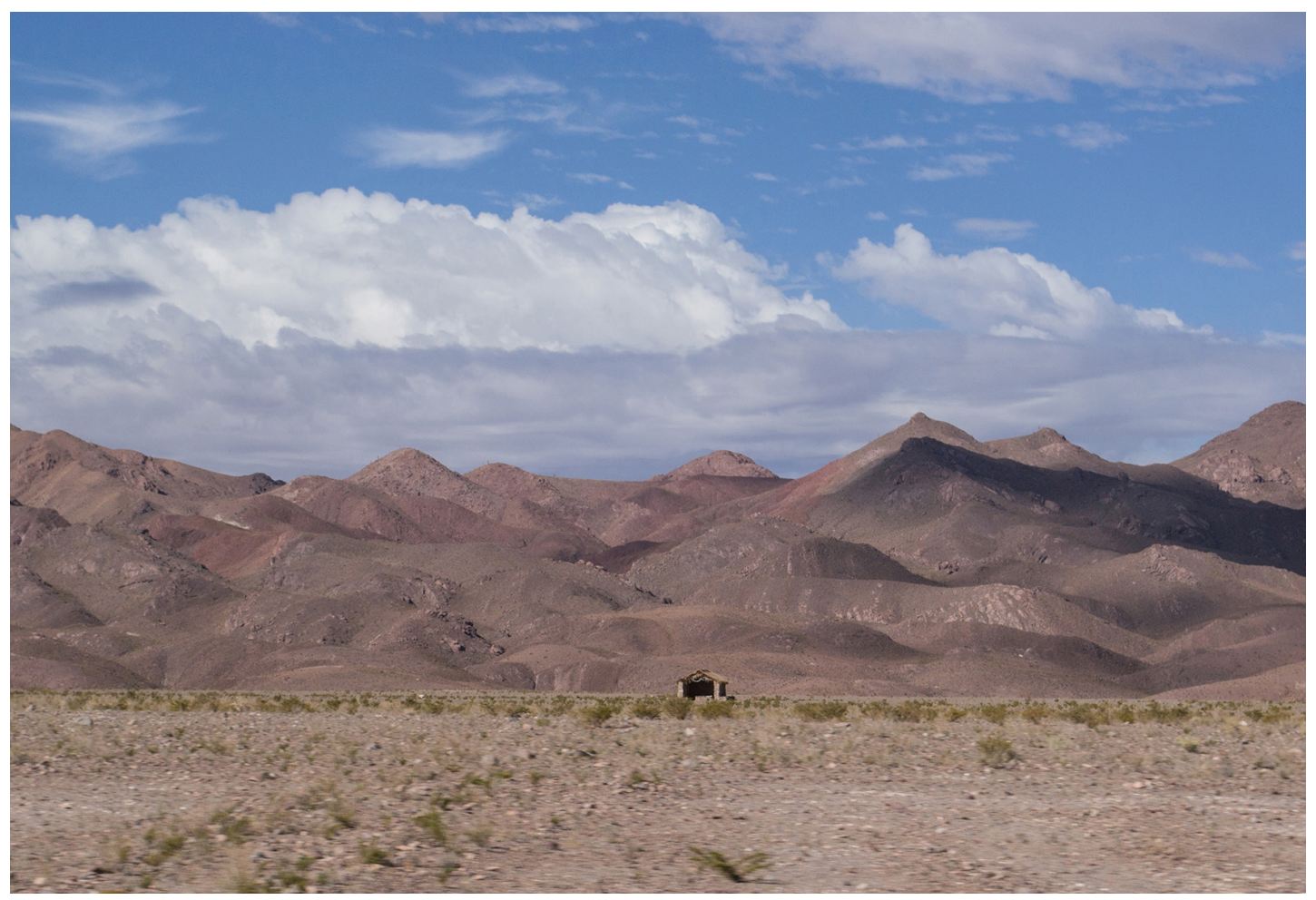

Figura 8. Altar en la lejanía y en perspectiva con los cerros. 


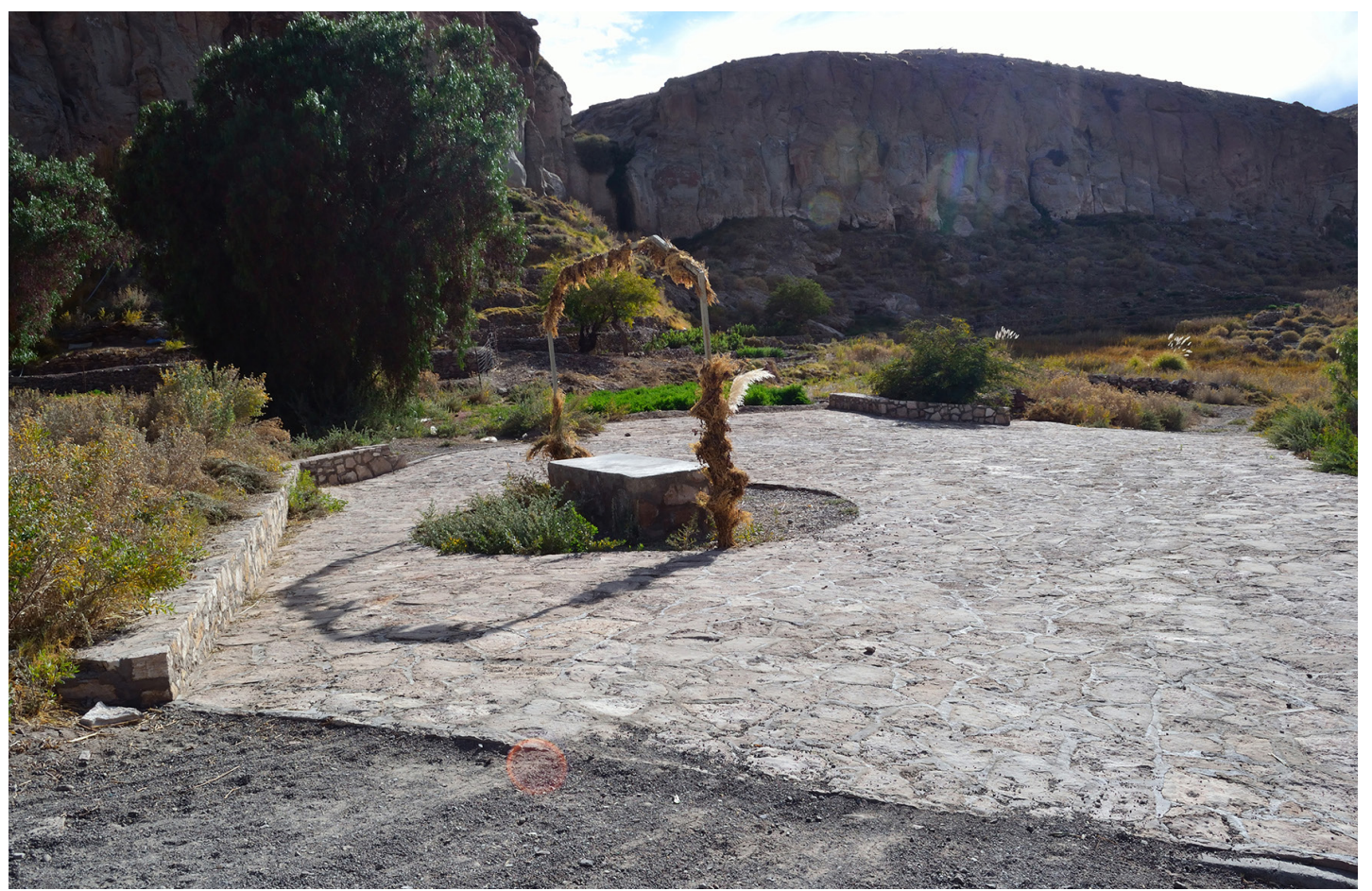

Figura 9. Altar en Ayquina junto al río.

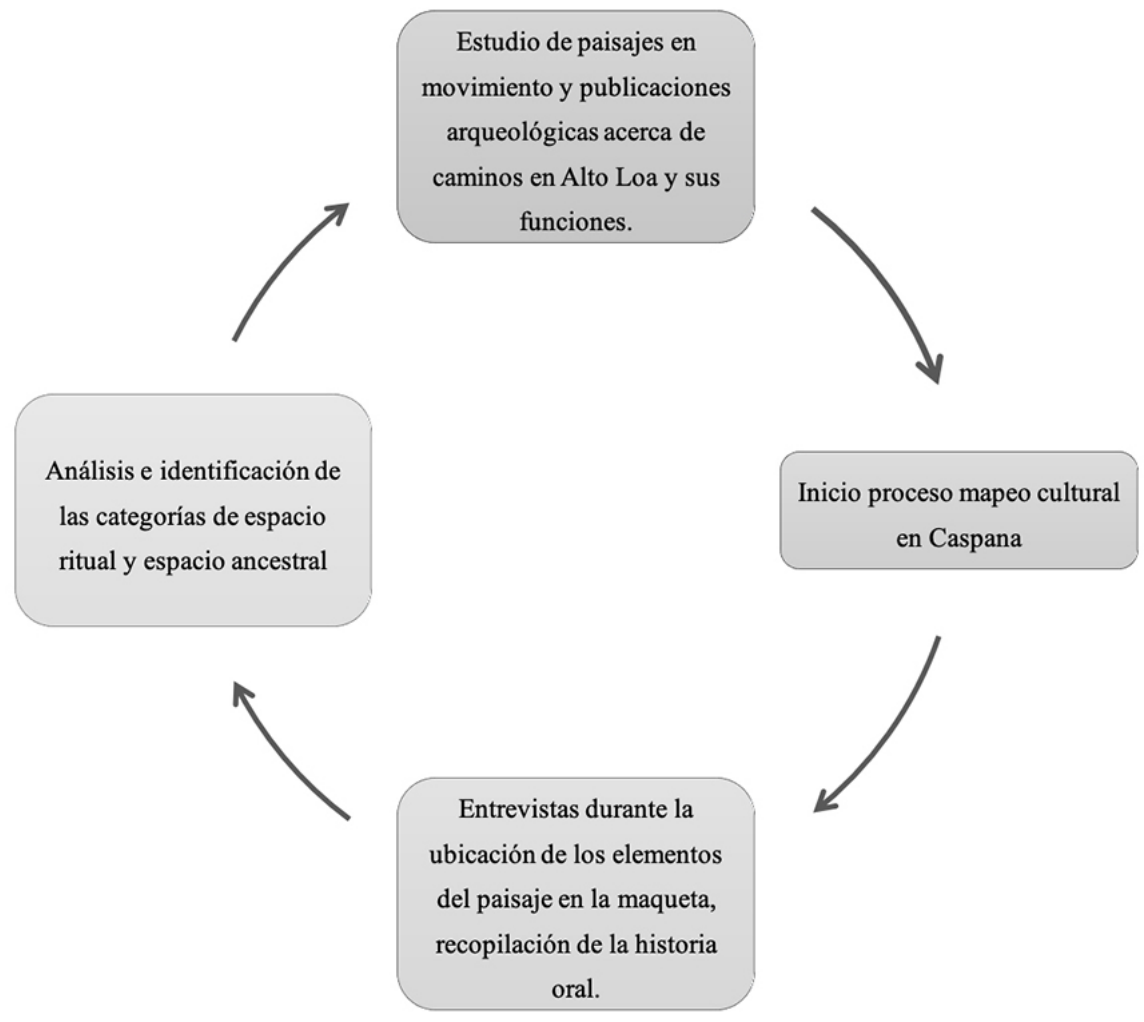

Figura 10. Diagrama metodología de paisaje en movimiento aplicada en el estudio. 
se detallan las procesos y las ideas que surgieron a partir de la aplicación de esta metodología de paisaje en movimiento.

La práctica y elaboración de "mapas culturales" propone un nuevo conjunto de reglas para hacer visible la forma en que las historias, prácticas, relaciones, recuerdos y rituales locales constituyen un lugar (Duxbury, Garret-Petts, and MacLennan, 2015). Por tanto, el enfoque se encuentra en los valores culturales de un grupo social. A partir del estudio y recopilación de diferentes técnicas de mapeo en comunidades indígenas, principalmente basados en el trabajo de Giacomo Rambaldi (2010), se resolvió proceder de la siguiente manera (ver Figura 11):

1. Selección del área de trabajo por el presidente de la comunidad de Caspana quienes ya estaban desarrollando un mapa de tenencia, en el momento de esta investigación y, por tanto, fue fácil definir el alcance del modelo.

2. Preparación de la leyenda del mapa con la comunidad. La comunidad ya había desarrollado un proceso participativo para el mapa de tenencia en proceso de aprobación. Los símbolos de la leyenda que ya habían identificado en el mapa eran los siguientes: pukaras, pintura rupestre, sitios arqueológicos de pueblos antiguos, lugares ceremoniales, colinas sagradas, escombros, arena, modas, apachetas, ollas, canteras, yeso, peces, estancias, carreteras, capillas, madera, turba, yaretas, agua para animales, zonas agrícolas, vega, cactus, paja, entre otros elementos.

3. Configuración de la maqueta. Rambaldi recomienda utilizar curvas de nivel para construir el modelo, trazarlas y luego cortarlas y pegarlas. A esto se incorporó utilizar una imagen satelital como base para ayudar a los participantes a ubicarse en un entorno desértico.

4. Selección de participantes para la interacción con la maqueta. Cuatro personas de Caspana visitaron la maqueta y accedieron a ser entrevistados mientras ubicaban y comentaban acerca de todos los elementos mencionados en la leyenda.

Las conversaciones durante el trabajo en la maqueta permitieron reunir diferentes narraciones y recuerdos de los participantes respecto de sus tierras y lugares que visitaban. En las conversaciones se les pedía a los participantes que se localizaran a sí mismos y los elementos que faltaban en los mapas, las historias que recordaban y cuál era el significado de los lugares señalados en el mapa. Esta actividad incentivaba la memoria oral y colectiva para quienes visitaban la maqueta en grupo. Se incluyeron dos nuevas características en el mapa durante las entrevistas: la toponimia (nombres de los lugares) y los guaras, o el origen de los lugares simbólicos del agua. De esta forma, los rituales aparecen constantemente asociados a las historias, como si fueran lugares o elementos tangibles en el paisaje.

Las conversaciones realizadas acerca de la maqueta transfirieron la ubicación de los sitios relevantes para la comunidad, reuniendo narrativas y recuerdos familiares hacia la tierra. Desde cactus, lugares sagrados, estancias a apachetas, fueron algunos de los elementos identificados sobre este mapa. A pedido de la comunidad el mapa revelando lugares sagrados no puede ser divulgado, sin embargo, uno de los descubrimientos fue la importancia de rituales como elementos presentes constantemente en sus historias, como si fueran lugares o elementos tangibles en el paisaje. Estos ritos se realizan sobre caminos que llevan a diferentes lugares dentro del territorio de Caspana, lo que explica la multiplicidad de caminos en torno al poblado como se puede observar en el mapa "Caminos tradicionales de Caspana" (ver Figura 12). Es muy probable que estos correspondan a los caminos caravaneros descritos por arqueólogos (Berenguer, Cáceres, Sanhueza, y Hernández 2005), sin embargo, es importante resaltar que en la voz de los miembros consultados durante el trabajo de campo se refieren a estos como caminos patrimoniales. Esto se debe a que actualmente se realiza en conjunto con CONADI y Consejo de Monumentos un trabajo de levantamiento de sitios patrimoniales, según fue informado en una visita en agosto de 2019.

"Exactamente, este es un camino patrimonial de Caspana que sale por aquí y encuentra con el camino del Inca, y el camino del Inca va a pasar por ahí (señala en el mapa). Este es un camino patrimonial (refiriéndose a otro, diferenciándolo del camino del Inca)" (Entrevistado B 2018).

La reflexión principal después de revisar las historias de diferentes personas de la comunidad y diversas narrativas en torno a los desplazamientos 


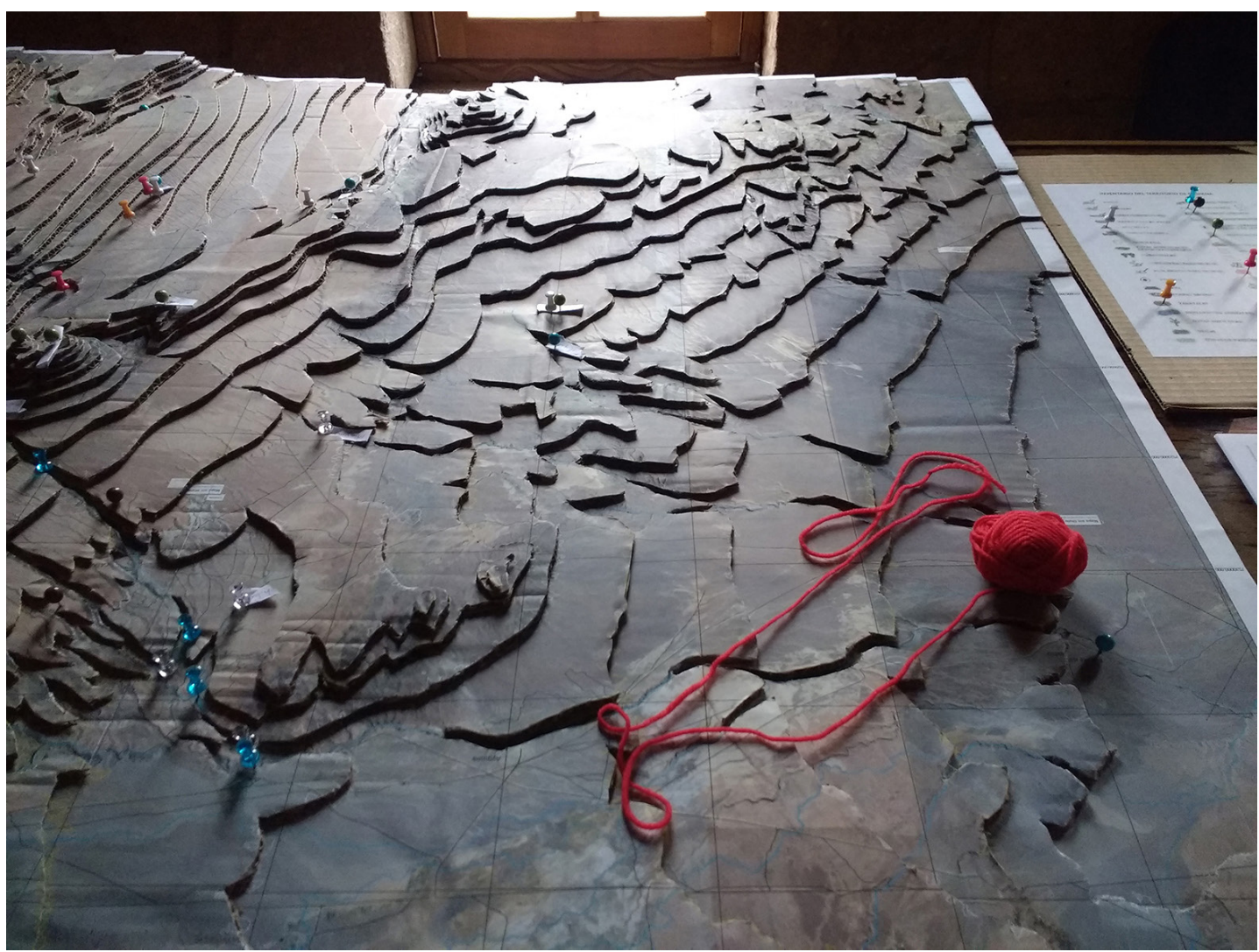

Figura 11. Maqueta de Caspana utilizado en el proceso de Mapeo cultural.

frente al modelo del territorio de Caspana, reveló una organización espacial territorial que articula dos espacios introducidos desde la teoría de "paisaje en movimiento", los que son el "espacio ancestral" y el "espacio ritual". Los elementos dispuestos en estas dos categorías evidencian dos características: los que permanecen visitados y los que ya no se visitan (ver Figura 13).

Las áreas ya no visitadas componen al espacio ancestral, donde las generaciones anteriores solían tener ganado junto a estancias, en donde pastaban animales en tierras compartidas con otras comunidades de Alto Loa (ver Figura 14). Este territorio se extiende desde los géiser del Tatio hacia el este, en donde se comparten tierras con Toconce; va hasta río Grande hacia el sur; la Quebrada del Diablo hacia el oeste, donde también se comparten tierras con Ayquina; y se extiende junto al río Salado como límite norte. Este es el espacio que la comunidad reconoce en la memoria de sus abuelos, donde antiguamente solían intercambiar residencias, asociado al pastoreo de animales que hoy se encuentran en estado salvaje en las tierras del altiplano. El Qhapaq Ñan o camino del Inca es un sendero que ya no se utiliza (ver Figura 15), por lo que también forma parte de este espacio ancestral junto con lugares donde se pueden encontrar turba, llaretas y cardones, además de los altares (ver figuras 6 y 7), los que ya no son utilizados para la peregrinación de los santos.

Acerca del sector de las llamadas "estancias" comentan:

"Era un lugar de pastoreo, un lugar donde se criaba mucho ganado antiguamente. Entonces ahí alojaban a muchas personas que eran de allá. Que vivían ahí, tienen sus casas que llamaban Estancias. Inclusive nosotros teníamos casa ahí. Una de ellas grande, muy grande en ese tiempo. Ahora ya no. Entonces ahí tenían ganado de llamos, de burros, de cabras, ovejas y hartos patos, animales silvestres, muchos animales silvestres" (Entrevistado C 2018). 


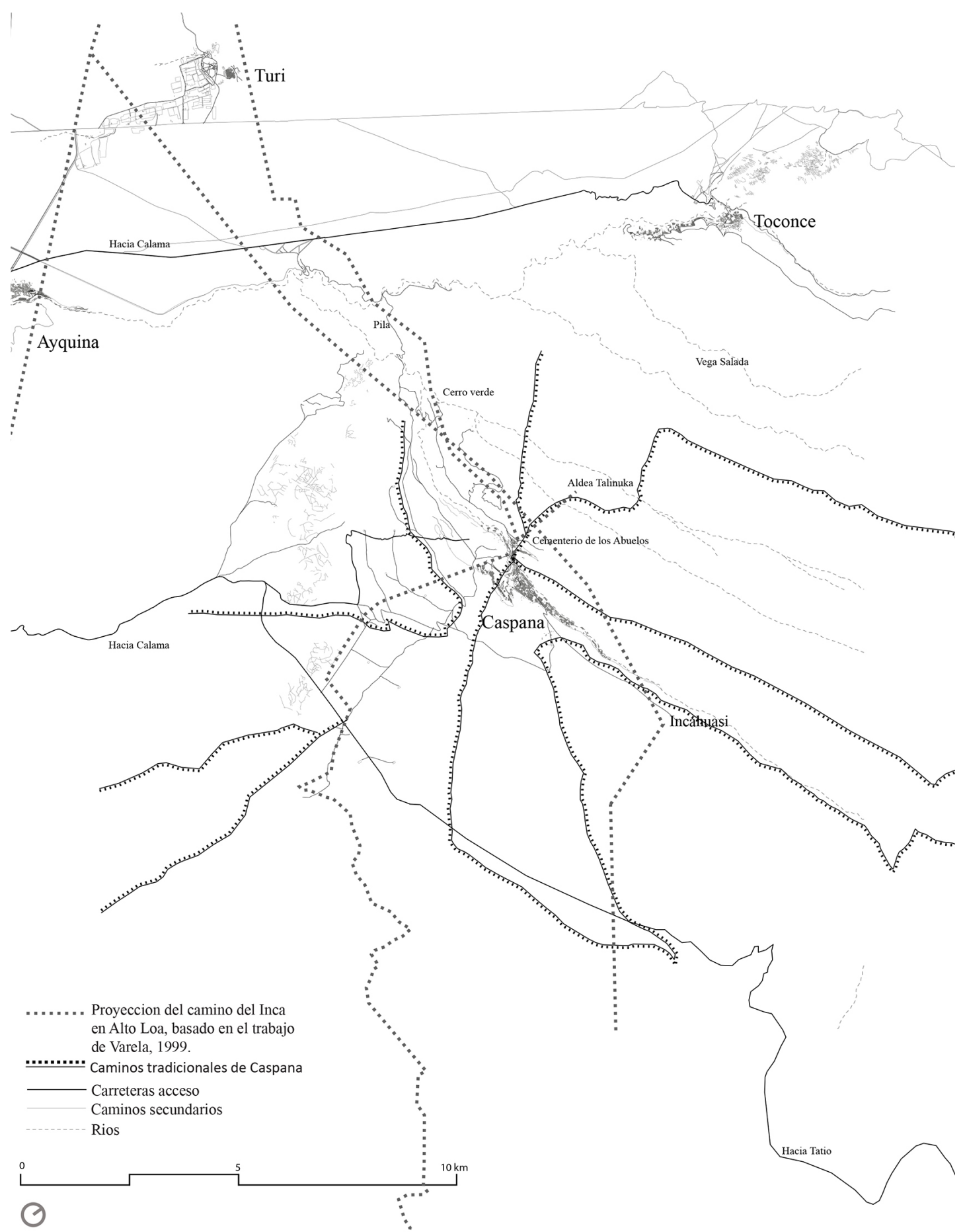

Figura 12. Plano caminos tradicionales de Caspana. 


\begin{tabular}{|c|c|c|}
\hline $\begin{array}{c}\text { Tipo de } \\
\text { movimiento }\end{array}$ & $\begin{array}{l}\text { Caminos hacia } \\
\text { elementos sagrados }\end{array}$ & $\begin{array}{l}\text { Caminos hacia } \\
\text { recursos }\end{array}$ \\
\hline $\begin{array}{c}\text { Hacia el } \\
\text { espacio ritual } \\
\text { (Sitios hoy } \\
\text { visitados) }\end{array}$ & $\begin{array}{l}\text { Cerros sagrados: Kablor, } \\
\text { Koller, Colorado. Son } \\
\text { considerados como cerros de } \\
\text { agua, hacia donde se hacen } \\
\text { rogativas por lluvia } \\
\text { Cuevas y lugares prohibidos. } \\
\text { Sitios sagrados que contienen } \\
\text { arqueologia o pintura rupestre. } \\
\text { Hoy existe una revalorización de } \\
\text { estos sitios. } \\
\text { Camino patrimonial, por donde } \\
\text { la comunidad se desplaza hacia } \\
\text { otros sitios rituales. }\end{array}$ & $\begin{array}{l}\text { Sectores donde se encuentra } \\
\text { paja para techumbre. } \\
\text { Madera } \\
\text { Laja (piedra) } \\
\text { Sitios de pastoreo junto a las } \\
\text { quebradas más próximas a Caspana } \\
\text { Guara o vertientes. Hoy estos } \\
\text { sitios están siendo revalorizados y } \\
\text { mapeados por la comunidad }\end{array}$ \\
\hline $\begin{array}{l}\text { Hacia el } \\
\text { espacio } \\
\text { ancestral } \\
\text { (Sitios no } \\
\text { visitados) }\end{array}$ & $\begin{array}{l}\text { Altares entre Toconce } \\
\text { y Ayquina. Estos } \\
\text { altares eran utilizados } \\
\text { por generaciones } \\
\text { anteriores para } \\
\text { peregrinarhacia los } \\
\text { poblados }\end{array}$ & $\begin{array}{l}\text { Búsqueda de Llaretas hoy no } \\
\text { permitida su extracción } \\
\text { Espacios compartidos con Ayquina, } \\
\text { Toconce y Rio Grande. Incluyen vegas } \\
\text { y el Tatio } \\
\text { Camino del Inca } \\
\text { Estancias para pastoreo } \\
\text { Pastoreo en vegas } \\
\text { Búsqueda de Turba, Cardones, como } \\
\text { madera para construcción. }\end{array}$ \\
\hline
\end{tabular}

Figura 13. Tabla categorías tipo de movimiento y elementos descritos por participantes.

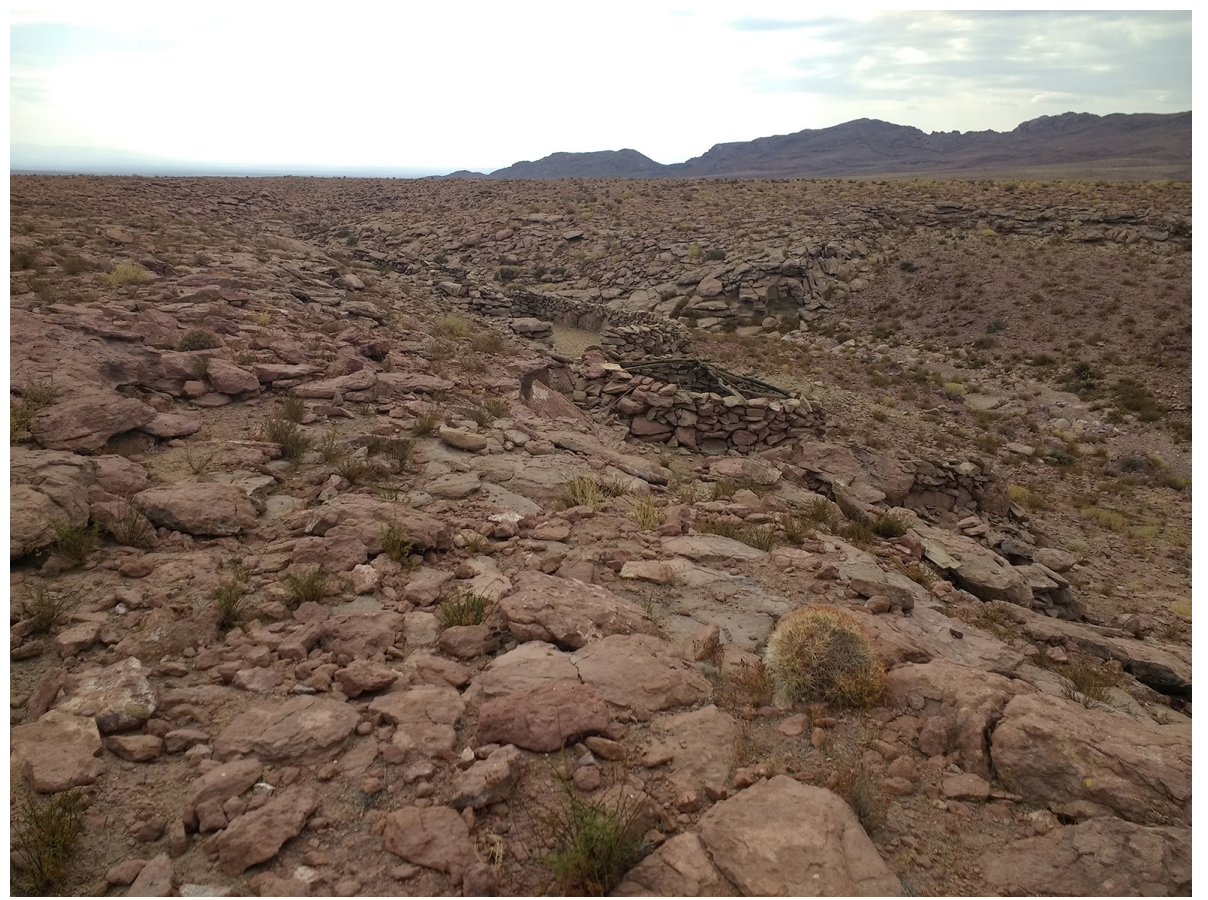

Figura 14. Estancia en las cercanías de Caspana. 


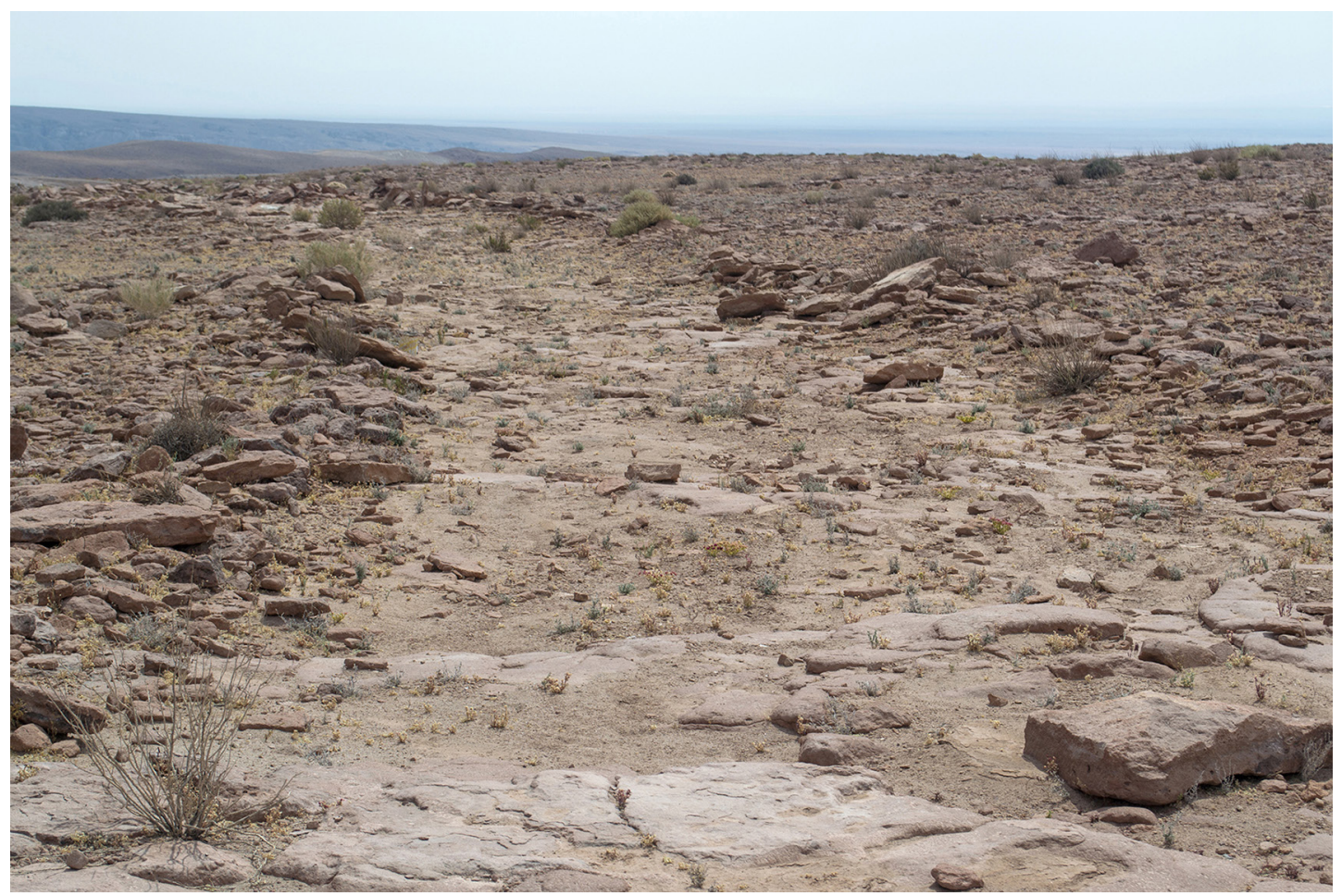

Figura 15. Qhapaq Nan o Camino del Inca, en Caspana.

La segunda categoría, el "espacio ritual", consiste en los elementos que hoy sí son visitados. Estos se reducen a pocas áreas donde la comunidad se desplaza para realizar pastoreo y para encontrar materiales para construir viviendas, como la piedra laja y paja. El movimiento se ha reducido a chakra (Martínez, 1985) y hacia la aldea de Caspana. Sin embargo, esta no sería la única vivienda de los pobladores, ya que poseen residencias alternativas (Imilan, 2007), una en Calama o Antofagasta en donde trabajan o estudian los hijos; y otra en Caspana donde mantienen sus cultivos o visitan para las celebraciones tradicionales y católicas. El espacio ritual se extiende hacia las quebradas mayores de Caspana, desde los sectores de Pila hasta Incahuasi. En estas áreas, los espacios rituales son reconocidos como lugares valiosos y catalizadores de la memoria y las tradiciones, son las áreas que permiten que las generaciones más jóvenes entren en contacto con el patrimonio de la cultura atacameña. Dos elementos han sido incorporados por medio de la evidencia observada durante el presente año, en dos proyectos de levantamiento territorial llevado a cabo por el presidente de la comunidad Germán González, en donde se mapearon todas las guaras o vertientes y sitios arqueológicos de Caspana ${ }^{2}$.

La limpia de canales, o la "ceremonia de limpieza del canal", consiste en varias prácticas, saludos y reconocimientos jerárquicos que acompañan la remoción de escombros y ramas del canal principal de agua de Caspana (Matus, 1993), el que se puede observar en el mapa "Canales y sitios agrícolas de Caspana" (Figuras 16 y 17). Es un ritual con significado más allá de la funcionalidad del canal, ya que refleja el compromiso de los miembros de la comunidad junto con prácticas comunitarias agrícolas que permiten la subsistencia de Caspana como es hoy. Para el ritual del Floramiento del Ganado, o el florecimiento del ganado, los animales se decoran en las orejas y el cuerpo con lanas de colores, que se dejan en los arbustos como pago a la tierra (Gleisner y Montt, 2014). Ambos rituales se realizan en sectores específicos de las cercanías al poblado, que pueden estar asociados con antiguos rituales espaciales hacia los cerros sagrados, que para esta comunidad corresponden al cerro Kablor y Koller (ver Figura 18). Son estos espacios los que albergan un patrimonio intangible, en mesas ceremoniales que solo se conforman una vez al año, 


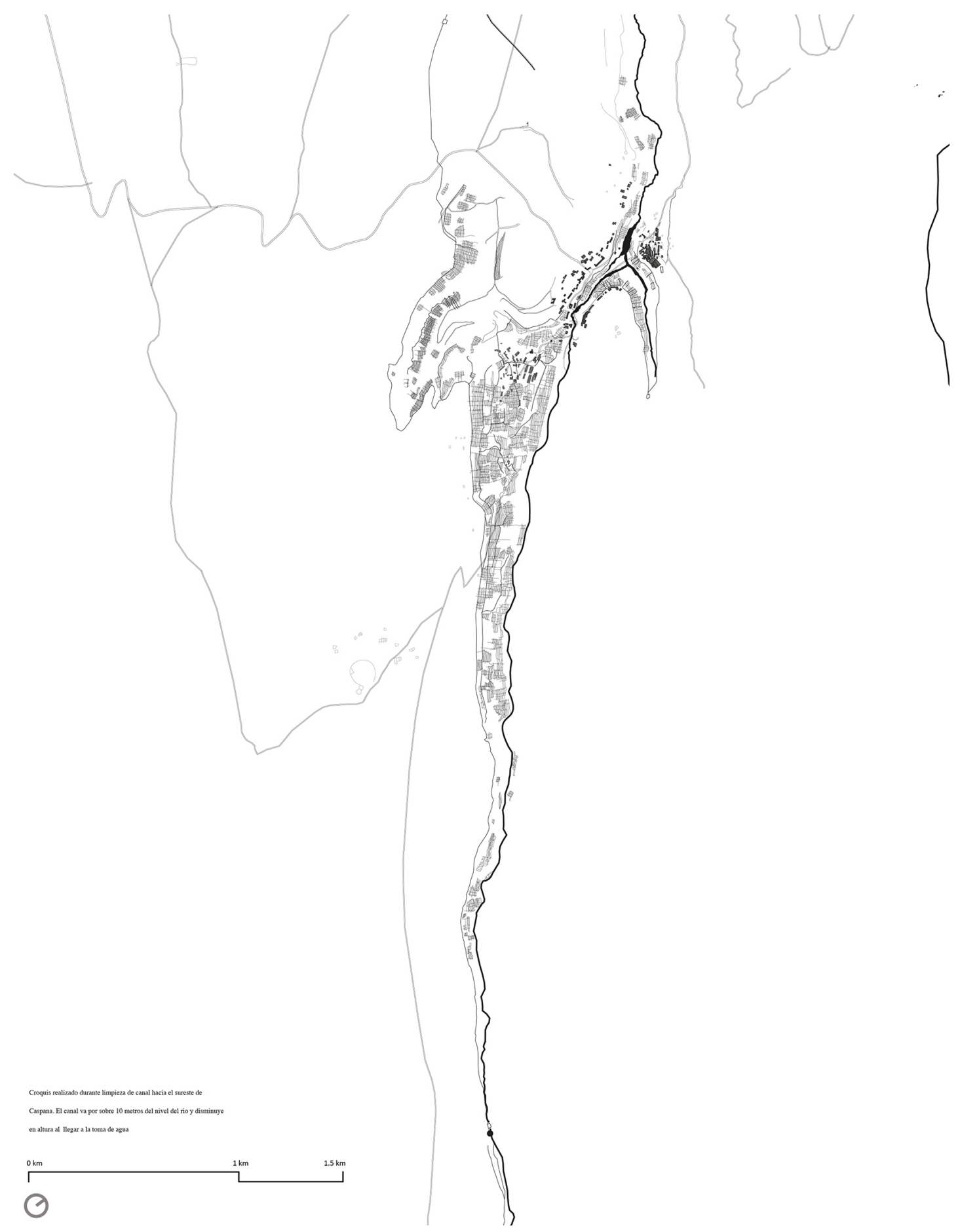

Figura 16. Plano de canales y sitios agrícolas de Caspana. 
que no poseen categoría de protección ya que no existe condición física en su categoría de inmaterial. Sin embargo, mediante un reconocimiento de los elementos que componen un paisaje en movimiento es posible articular espacios, territorios en donde el rito se materializa.

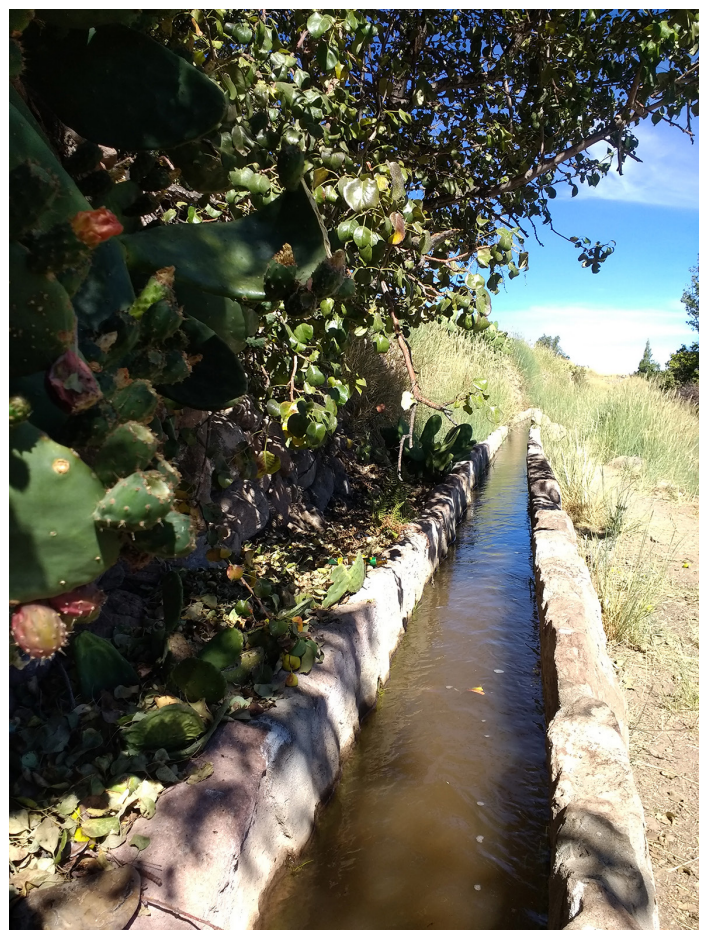

Figura 17. Canal central hacia el sur de Caspana.
Esto comentan acerca de la limpia de canales:

"Donde se limpia el canal matriz que abastece con agua el pueblo, pero igual ahí son varios días de trabajo comunitario. Tiene sus costumbres, sus tradiciones aparte. Igual es una costumbre que se recuerda mucho, en realidad la gente no lo quiere dar a conocer porque es más propio de la comunidad" (Entrevistada A 2018).

Finalmente, el paisaje en movimiento de Caspana está representado por diversos elementos, desde toponimias en el idioma kunza, petroglifos que señalan direcciones y símbolos, ceremonias y rituales a lo largo de tierras compartidas con otras comunidades en torno al antiguo uso de sectores para pastoreo. Estos elementos se encuentran articulados en el paisaje como un palimpsesto de rasgos y la memoria de un antiguo espacio ancestral. El movimiento de hoy no es el mismo movimiento que se practicó en el pasado. Ambos territorios son esenciales y poseen un valioso patrimonio, que hoy se encuentra en peligro por los proyectos de exploración minera, sin embargo, al otorgar a las comunidades un mayor conocimiento de las características que componen estos territorios, se logra como primera etapa aumentar la protección de estos lugares.
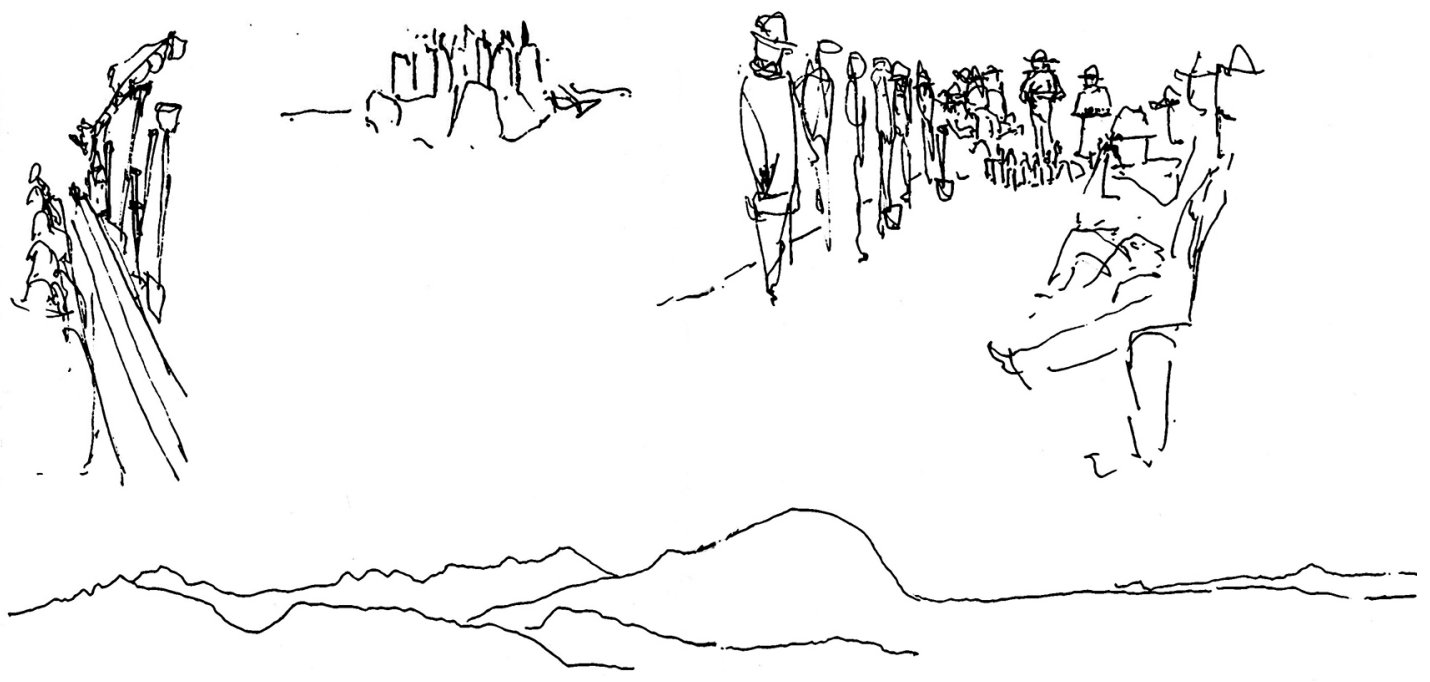

Figura 18. Croquis limpia de canales. 


\section{Conclusiones}

Este artículo ofrece una metodología compuesta de varios procedimientos, desde el trabajo de mapeo cultural, al registro etnográfico y luego clasificación a partir de teoría de paisaje en movimiento que buscan integrar la localización y valorización del patrimonio cultural inmaterial junto con el patrimonio arqueológico en comunidades atacameñas.

La teoría de paisaje en movimiento permite entender, desde una perspectiva histórica y actual, cómo el espacio se articula uniendo lo material con lo inmaterial, la memoria y la ritualidad. La protección de lo intangible es posible al ubicar los ritos y las tradiciones como un camino o el área donde se llevan a cabo, y en este caso, valorar el movimiento como una representación física asociada con vestigios arqueológicos reconocidos por las comunidades.

La distinción entre el territorio "antiguo" y el "ritual" es esencial para especificar estas áreas de valor intangible. Hoy, el espacio ancestral está reconocido como territorio de la comunidad de Caspana, sin embargo, está expuesto a un sinnúmero de peligros potenciales, principalmente en manos de la extracción minera, ya que el subsuelo no pertenece a la comunidad sino al Estado de Chile. En el espacio ritual, el patrimonio intangible se encuentra en los lugares donde se practicaban los ritos antiguos, la pintura rupestre que conectan los lugares sagrados con interpretaciones del pasado en las figuras y todas las características que componen el mapa de tenencia de Caspana como un inventario de su patrimonio. Además, se caracteriza por ser un sector de alto valor histórico que requiere de una puesta en valor que permita a las futuras generaciones conocer su pasado para enfrentar su presente.

La localización de estas características se convierte en un argumento legal para la protección del patrimonio. Individualmente, estos elementos podrían tener protección solo si se consideran arqueológicamente valiosos. Lugares como sitios ceremoniales, sin construcciones visibles o vestigios de culturas anteriores, no tienen protección en términos de patrimonio. Al juntar todos estos elementos, adquieren valor en conjunto. El mapa como inventario permite a la comunidad solicitar la protección de todos estos sitios como parte de su patrimonio cultural.

Sin embargo, los hallazgos de estas investigaciones, especialmente la ubicación de los lugares sagrados, también puede convertirse en un arma contra las comunidades que los valoran, cuando se convierte en información que no desean compartir. Esa es la razón por la que, como requisito de la comunidad, esta tesis no revela localizaciones, a pesar de que la investigadora está al tanto de todos los lugares ubicados en el mapa.

\section{Agradecimientos}

Estoy agradecida con la comunidad de Caspana por compartir sus conocimientos que me permitieron completar mi MPhil. También reconozco el fondo recibido por CONICYT (Comisión Nacional de Investigación Científica y Tecnológica / Comisión Nacional de Investigación Científica y Tecnológica de Chile) "Becas Chile", Programa de becas maestras; Donación No. 73171337 a Melisa Miranda Correa.

\section{Referencias Citadas}

Adán, L., y Uribe, M.

2005 "El dominio Inca en la localidad de Caspana: Un acercamiento al pensamiento político andino". Estudios Atacameños, 29, 41-66.

Berenguer, J., Aldunate, C., y Castro, V.

1982 Orientación Orográfica de las Chulpas en Likan: La importancia de los cerros en la Fase Toconce. In B. Bittman (Ed.), Simposio: Culturas Atacameñas. 175-220.

Berenguer, J., Cáceres, I., Sanhueza, C., y Hernández, P. 2005 "El Qhapaq ñan en el Alto Loa, norte de Chile: Un estudio micro y macromorfológico". Estudios Atacameños, 7-39.

Berenguer, J., y Salazar, D.

2017 "Territorialización del modelo minero Inkaico en el Río Salado: Una aglomeración productiva entre Lípez y
San Pedro de Atacama”. Boletín del Museo Chileno de Arte Precolombino, 22.

Besom, $\mathrm{T}$.

2009 Of Summits and Sacrifice. An ethnohistoric study of Inka Religious practices: University of Texas Press.

Brugman, F.

2012 "Culture and development. Cultura y desarrollo". UNESCO, 7, 4-6

Careri, F.

2002 Walkscapes, el andar como práctica estética. Editorial Gustavo Gili, Barcelona.

Castro, V., y Martínez, J. L.

1996 "Poblaciones indígenas de Atacama". In J. Hidalgo, V. Schiappacasse, H. Niemeyer, C. Aldunate, y P. Mege (Eds.), Culturas de Chile, Etnografía. Sociedades Indígenas 
contemporáneas y sus ideologías. Santiago de Chile: Editorial Andrés Bello. 69-109.

Clarke, P.

2003 Where the Ancestors Walked. Australia as an aboriginal Landscape. National Library of Australia: Allen and Unwin. Corvalán, C.

2015 La implementación de "la consulta" del convenio 169 de la OIT en Chile: Las implicancias para la Gran Minería. Universidad de Chile, Santiago de Chile.

Darlin, J. A.

2009 "O'odham trails and the Archaeology of space". In J.

Snead, C. Erickson, and A. Darling (Eds.), Landscapes of Movement: Trails, Paths, and Roads in Anthropological Perspective. Pennsylvania: University of Pennsylvania Press, Museum of Archaeology and Antropology. 61-83

Díaz A., A., Galdames, L., and Mucous, W.

2012 "Santos Patronos en Los Andes. Imagen, símbolo y Ritual en las fiestas Religiosas del Mundo Andino Colonial (Siglos WVI-XVII)". Alpha, 35, 23-39.

Duxbury, N., Garret-Petts, W. F., and MacLennan, D.

2015 Cultural Mapping as Cultural Inquiry. New York: Routledge

Eliade, $\mathrm{M}$.

1959 The sacred and the profane: the nature of religion. New York: Harcourt.

Erickson, C. L.

2009 "Agency, Causeways Canals and the Landscape of Everyday life in the Bolivian Amazon". In J. Snead, C. Erickson, and J. A. Daring (Eds.), Landscapes of Movement: Trails, Paths, and Roads in Anthropological Perspective. 204-231.

Ferguson, T., Lenis, B. G., and Kuwanwiswma, L.

2009 "Kukhepya: Searching for Hopi Trails". In J. Snead, C. Erickson, \& A. Darling (Eds.), Landscapes of Movement: Trails, Paths, and Roads in Anthropological Perspective. 20-42

Gartner, W.

1998 "Mapmaking in Central Andes". In D. Woodward and M. Lewis (Eds.), Cartography in the Traditional African, American, Arctic, Australian, and Pacific Societies. Chicago: University of Chicago Press. Vo 2, Book 3, 257-300.

Gleisner, C., y Montt, S.

2014 Atacameños. Serie: Introducción histórica y relatos de los pueblos originarios de Chile Santiago, Chile.: Fundación de Comunicaciones, Capacitación y Cultura del Agro, Fucoa.

González, S., Aguilar, J., y Garrido, F.

2015 Qhapaq Nan - El Sistema Vial Andino y los Incas en el Norte de Chile. Dibam, CMN, Santiago de Chile.

Harris, O.

1997 "Los límites como problema: mapas etnohistóricos de los Andes bolivianos". In T. Bouysse-Cassagne (Ed.), Caberes y memorias en Los Andes. In Memoriam Thierry Saignes. Paris: Éditions de I'IHeal. 294-313

Imilan, W.

2007 "Socaireños en movimiento. Atacameños y Calama". Estudios Atacameños, 33, 105-123.

Ingold, T.

2012 "The Shape of the Land". In A. Árnason, N. Ellison, J. Vergunst, and A. Whitehouse (Eds.), Landscapes beyond Land: Routes, Aesthetics, Narratives. New york: Berghahn Books. Vol. 44, 197-208.
Ingold, T.

2015 The life of lines. Milton Park, Abingdon, Oxon; New York, NY: Milton Park, Abingdon, Oxon ; New York, NY: Routledge.

Keller, A. H.

2009 "A road by any Other Name: Trails, Paths and Roads in Maya Language and Thought”. In J. Snead, C. Erickson, and J. A. Daring (Eds.), Landscapes of Movement: Trails, Paths, and Roads in Anthropological Perspective. Pennsylvania: University of Pennsylvania Press. 133-157.

Lazo, A., Riquelme, H., y Huiliñir-Curío, V.

2020 "La movilidad en su ambiente: prácticas y experiencias de movilidad cotidiana Mapuche-Williche en contextos rurales. Evidencias desde la comuna de Puyehue, región de Los Lagos, Chile". Diálogo Andino, 62, 5, 17.

Lynch, T. F.

1993-1996 "Inka roads in the Atacama: Effects of later use by mounted travellers". Diálogo Andino, 187.

Martínez, J. L.

1985 "La formación del actual pueblo de Toconce (siglo XIX)". Revista Chungara, 15, 99-124.

Matus, A. I.

1993 "El ceremonial de la limpia de canales en Caspana". Revista Chilena de Antropología, 12, 65-86.

Mercado, J.

2014 "Práctica Ritual y Tensiones Identitarias en las Danzas Protestantes de la fiesta del Santuario de Ayquina, Norte de Chile". Diálogo Andino, 45, 193-213.

Monumentos, $\mathrm{C}$.

2016 Plan Maestro para la Conservación y Gestión del Qhapaq Ñan Santiago, Chile: DIBAM.

\section{MINEDUC}

1970 Legisla sobre Monumentos nacionales; Modifica las leyes 16.617 y 16.719: Deroga el Decreto de Ley 651, de 17 de octubre de 1925. Chile: Biblioteca del Congreso Nacional de Chile Retrieved from http://www.monumentos.cl/sites/ default/files/ley-17288_reforma_2018.pdf

MINEDUC

1990 Reglamento sobre excavaciones y/o prospecciones arqueológicas, antropológicas y paleontológicas. Chile: Diario Oficial.

OIT

2006 Convenio 169 de la OIT. Sobre pueblos indígenas y tribales en países independientes. In O. I. d. T. Chile (Ed.). Santiago, Chile: Andros Impresores.

Pino Matos, J. L.

2016 "Qhapaq ñan wamanin: los lugares de libación como hitos de la memoria en cada paisaje sagrado de la ruta principal hacia el Chinchaysuyu". Diálogo Andino, 49, 167-180.

Rambaldi, G.

2010 Participatory three-dimensional modelling: Guiding Principles and application. In: ACP-EU Technical Centre for Agricultural and Rural Cooperation (CTA).

Salazar, D., Berenguer, J., y Vega, G.

2013 "Paisajes minero-metalúrgicos incaicos en Atacama y el altiplano sur de Tarapacá (norte de Chile)". Chungara, Revista de Antropología Chilena, 45, 83-103.

Salazar, G., Fonck, M., e Irarrázaval, F.

2017 "Paisajes en movimiento: sentidos de lugar y prácticas interculturales en ciudades de la región de La Araucanía, Chile". Chungara, 49(2), 251-264. 
Sanhueza, C.

2008 "Territorios, prácticas rituales y demarcación del espacio en Tarapacá en el siglo XVI". Boletín del museo Chileno de Arte Precolombino, 13, 57-75.

Sanz, N.

2012 "El Qhapaq Ñan: Camino del desarrollo andino. Revista Cultura y Desarrolo. Oficina regional de Cultura para América Latina y el Caribe". Unesco La Habana. № 7, 43-46.

Sinclaire, C.

2004 "Prehistoria del período formativo en la cuenca alta del Río Salado (Región del Loa superior)". Chungara, Revista de Antropología Chilena, Volumen especial, 619-639.

Snead, J.

2009 "Trails of tradition: movement, meaning and place". In J. E. Snead, Clark and A. Darling (Eds.), Landscapes of Movement: Trails, Paths, and Roads in Anthropological Perspective. 42-60.

Snead, J., Erickson, C., and Daring, J. A.

2009 Landscapes of Movement: Trails, Paths, and Roads in Anthropological Perspective. Pennsylvania: University of Pennsylvania Press.

Snead, J., Erickson, C., and Darling, A.

2009 "Making Human Space: The Archaeology of Trails, Paths, and Roads". In J. E. Snead, Clark and A. Darling (Eds.), Landscapes of Movement, Trails, Paths, and Roads in Anthropological Perspective. 1-19.

Desarrollo Social, Ministerio

2016 Informe desarrollo social. In M. d. d. social (Ed.). Chile.
Solnit, R.

2002 Wanderlust: a history of walking (New edition. ed.): London; New York: Verso.

Tilley, C.

2012 "Walking the Pas in the Present". In A. E. Árnason, Nicolas, J. Vergunst, and A. Whitehouse (Eds.), Landscapes beyond Land: Routes, Aesthetics, Narratives (pp. 15-32). New York: Berghahn Books.

\section{UNESCO}

2003 Convención para la Salvaguardia del Patrimonio Cultural Inmaterial.

UNESCO

2014a Executive summary: Qhapaq Ñan, Andean Road System. UNESCO.

\section{UNESCO}

2014b Qhapaq Ñan, Andean Road System. 2018.

Varela G., V.

1999 "El Camino del Inca en la cuenca superior del río Loa, desierto de Atacama, Norte de Chile". Estudios Atacameños, 18. 89-105.

Villanueva Gallardo, S.

2019 "Aproximación metodológica al concepto de territorios discursivos". Diálogo Andino, 59. 55-63.

Vitry, C.

2017 "El rol del Qhapaq nan y los Apus en la expansión del Tawantinsuyu". Boletín del Museo Chileno de Arte Precolombino, Vol. 22, 35-49

\section{Notas}

1 La comunidad de Caspana se considera una comunidad cerrada, en donde un investigador no puede simplemente ir y recoger datos. Para trabajar ahí tuve que acercarme a la comunidad en diciembre de 2017 y llevar un plan de trabajo, el que fue estudiado por la directiva de ese año. Ellos mismos fueron quienes solicitaron continuar con el mapa de tenencia que ya habían comenzado, lo que coincidía con mi plan de realizar mapas culturales según el método definido por Rambaldi (2010). Luego en enero 2018 asistí a una reunión de comuneros en donde volví a presentar mi propuesta, la de realizar el mapa y fue ahí en donde se autorizó mi trabajo. Luego, tuve que llevar una carta en donde me comprometía a no divulgar la localización de los límites de la comunidad ni de ningún lugar sagrado. También me comprometí a llevar todos los resultados de la investigación impresos y en un respaldo digital a la comunidad.

2 Esta información ha sido recopilada a partir del trabajo colaborativo que la autora realiza con esta comunidad. Es importante mencionar que durante todo el 2020 y principios del 2021 ha sido llevado a cabo en línea. Resultados de la presente investigación serán publicados más adelante. 